\title{
PROBABILITY DENSITY FUNCTIONS \\ OF BREAKING WAVES
}

\author{
George Schaeffer
}





\section{NAVAL POSTGRADUATE SCHOOL Monterey, California}
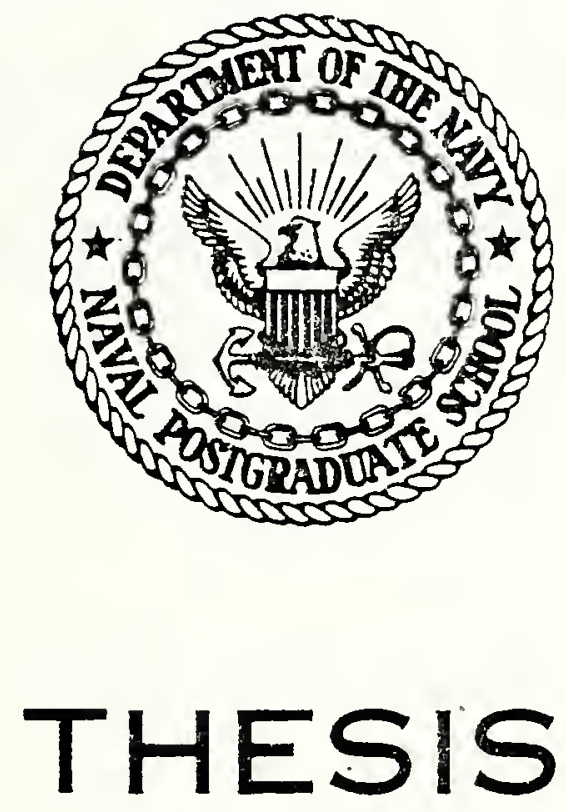

\section{PROBABILITY DENSITY FUNCTIONS OF BREAKING WAVES}

by

George Schaeffer II

June 1978

Thesis Advisor:

E. B. Thornton

Approved for public release; distribution unlimited.

1184583 



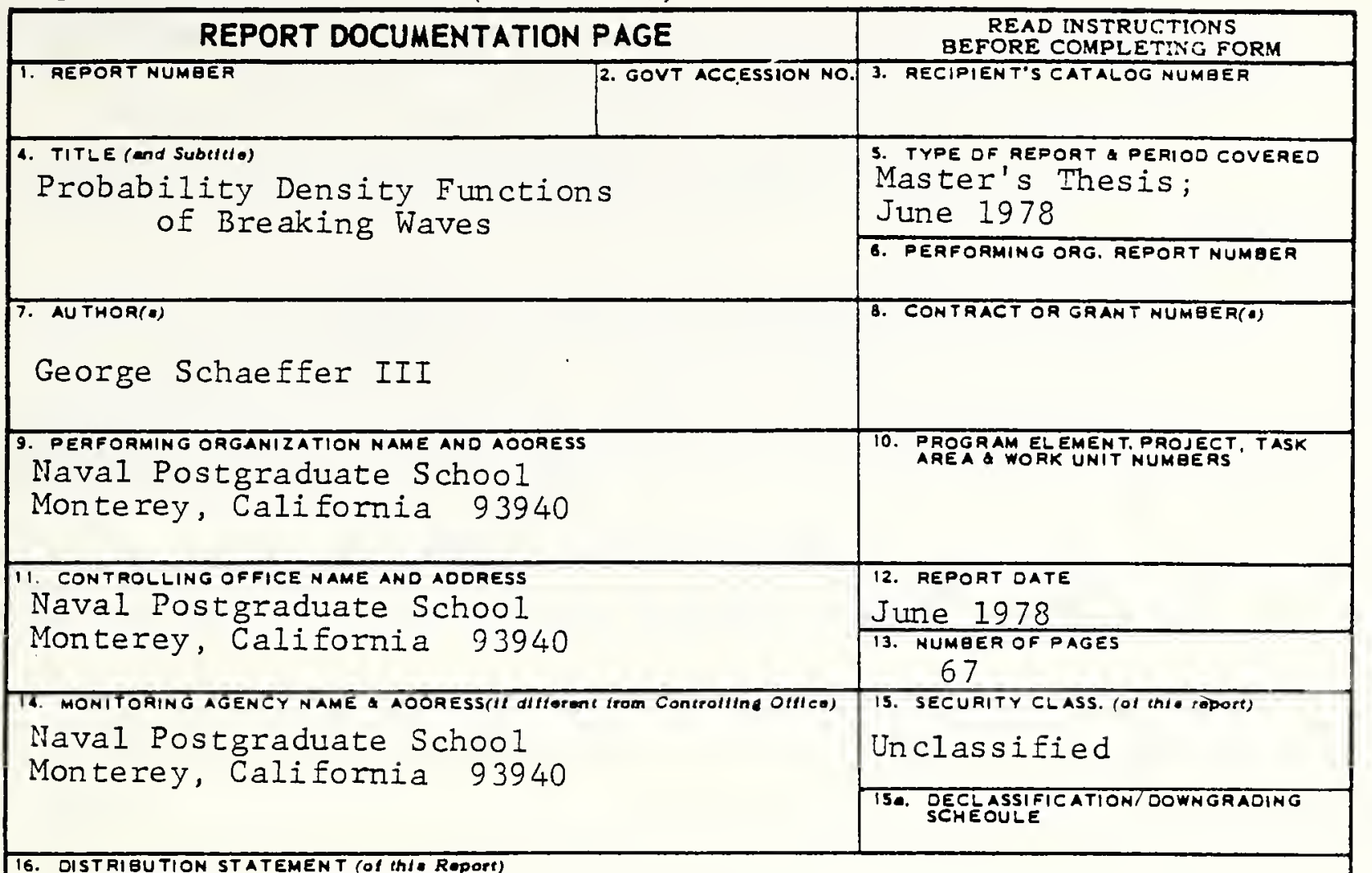

Approved for public release; distribution unlimited.

17. DISTRIBUTION STATEMENT (of the ebotrect entered in Block 20, II different from Roport)

18. SUPPLEMENTARY NOTES

19. KEY WOROS (Continue on revoree elde Il necuecary end ldentlfy by block nuenber)

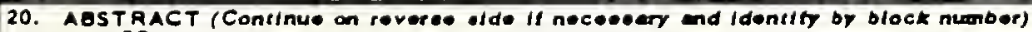

Waves in the surf zone are a highly nonlinear process which is evident by the appearance of secondary waves. The secondary waves appear as strong peaks in the period PDFs corresponding to the first harmoric of the peak of the wave spectrum. The $3 t x o n g$ first harmonic period peak is also reflected in the highly correlated height and velocity PDFs. 

Breaking waves may be viewed as a gradation between two extremes. The period, height and velocity PDFs for spilling breakers generally were unimodal, whereas for plunging breakers strong bimodality was found.

The joint probability density functions for periods and heights of the breaking waves show high correlation (0.600.30 ) which says that greater wave periods are associated with larger breaker heights. The joint PDFs of period and particle velocity, and velocity height, suggest that the maximum onshore particle velocities are correlated with both the wave periods and wave heights.

Due to the high probability of the secondary waves, the mean wave period for breakers is a poor descriptor of the average period of the offshore incident waves. 

Approved for public release; distribution unlimited.

$$
\begin{gathered}
\text { Probability Density Functions } \\
\text { of Breaking Waves }
\end{gathered}
$$

$$
\text { by }
$$

George Schaeffer III

Lieutenant, United States Navy

B. S., Albright College, 1971

Submitted in partial fulfillment of the requirements for the degree of

MASTER OF SCIENCE IN OCEANOGRAPHY

from the

NAVAL POSTGRADUATS SCHOOL

June 1978 
Thes is

$$
\text { S } 246
$$




\section{ABSTRACT}

Waves in the surf zone are a highly nonlinear process which is evident by the appearance of secondary waves. The secondary waves appear as strong peaks in the period PDFs corresponding to the first harmonic of the peak of the wave spectrum. The strong first harmonic period peak is also reflected in the highly correlated height and velocity PDFs.

Breaking waves may be viewed as a gradation between two extrenes. The period, height and velocity PDFs for spilling breakers generally were unimodal, whereas for plunging breakers strong bimodality was found.

The joint probability density functions for periods and heights of the breaking waves show high correlation (0.60$0.80)$ which says that greater wave periods are associated with larger break:er heights. The joint PDFs of period and particle velocity, and velocity and height, suggest that the maximum onshore particle velocities are correlated with both the wave periods and wave heights.

Due to the high probability of the secondary waves, the mean wave period for breakers is a poor descriptor of the average period of the offshore incident waves. 

TABLE OF CONTENTS

I. INTRODUCTION - - - - - - - - - 8

II. HISTORICAL BACKGROUND - - - - - - - - 10

A. QUAlitative Description - - - - - - 10

B. ENERGY DENSITY SPECTRA

OF BREAKING WAVES - - - - - - - - 12

C. PROBABILITY DENSITY FUNCTIONS

OF PERIODS AND HEIGHTS - - - - - - - 13

D. JOINT PROBABILITY DENSITY FUNCTIONS - - - 19

III. EXPERIMENT - - - - - - - - - - 24

A. EXPERIIIENTAL SITES - - - - - - - - 24

B. IISTRUIIENTS - - - - - - - - - 25

C. DATA AIIALYSIS - - - - - - - - 26

IV. DISCUSSION - - - - - - - - - - 32

A. PERIOD PROBABILITY DENSITY FUNCTIONS - - - 33

B. HEIGHT PROBABILITY DENSITY FUNCTIONS - - - 33

C. JOINT PROBABILITY DENSITY FUNCTIONS

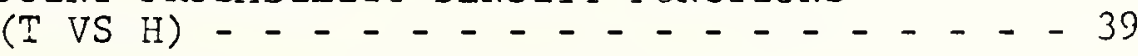

D. VELOCITY PROBABIIITY DENSITY

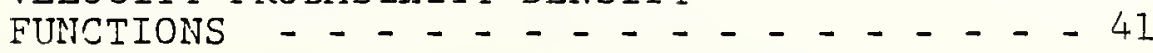

E. JOINT PROBABILITY DEISITY FUNCTIONS

(V VS H) - - - - - - - - - - 41

F. JOINT PROBABILITY DENSITY FUNCTIONS

( $($ VS V) - - - - - - - - - - 44

V. CONCLUSIONS - - - - - - - - - - 48 

APPENDIX A. Statistical Parameters Calculated - - - 51 APPENDIX B. Mathematical Derivation of Normalized Rayleigh Distributions - - - 54 APPENDIX C. Probability Density Functions - - - - 56 BIBLIOGRAPHI - - - - - - - - - - - - 64 IIITIAL DISTRIBUTION LIST - - - - - - - - 66 



\section{LIST OF FIGURES}

1. Strip Chart Record of Sea Surface Elevations and Particle Velocities - - - - - 11

2. Energy Density Spectra of $n$ and $v$, 4 March 1975

3. Statistically Independent Joint Rayleigh PDF _ - _ _ _ _ - - - - 21

4. Low Pass Digital Filter - - - - - - - - 28

5. PDFs of Period and Height, 16 March 1977 _ . _ _ . . . . . . . 34

6. PDFs of Period and Height, 4 March 1975 _. . _ . . . . . . . . 35

7. PDFs of Period and Height, 30 bin, 4 March 1975 - _ . . . - . - - 37

3. PDFs of Velocity and Height, 16 March 1977 _ . - _ . . . . . . . 42

9. PDFs of Velocity and lleight, 4 March 1975 _ _ _ _ . . . . . - . 43

10. PDFs of Period and Velocity, 16 March $1977^{\prime}$ - . _ _ . . . . . . - 45

11. PDFs of Period and Velocity,

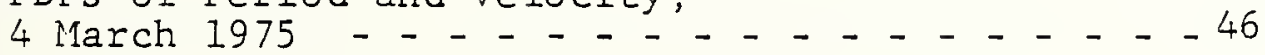





\section{INTRODUCTION}

Waves in deep water can generally be represented to a first approximation as a Gaussian process having zero skewness and kurtosis equal to three. The random sea surface is viewed as the linear superposition of statistically independent spectral components which is adequately described by the energy density spectrum. The restriction of statistical independence implies the wave components act as free waves and there is no coupling or interaction between various spectral components.

As the waves begin to shoal, the crests become more peaked, and the troughs become more elongated; this results in a positive value of the third statistical monent, i.e., the probability density distribution of sea surface elevations becomes skewed to the right. The skewness is a result of phase coupling of the wave components, which is indicative of the increasing importance of the non-linearities of the system. This initially weakly non-linear system found in shallow water may be adequately described by a Gram-Charlier probability distribution (Longuet-Higgins, 1963).

Near breaking waves become asymmetrical about the crest with a continually steepening of the wave face. Miller (1976) has shown that a jet is then formed at the wave crest at breaking, which extends fortard and then down 

until it closes with the forward face of the breaking wave form. The asymmetry about the wave crest yields a change in the fourth moment, or kurtosis, which is also indicative of the increasing non-linearities. Thomton et al. (1976) have noted that secondary wave formation becomes apparent on the trailing face of the wave form, due to transfer of energy from the primary frequency to its harmonics which also points to a strongly nonlinear system.

This thesis uses data collected as described by Galvin (1975) and Olsen (1977) plus additional data collected by the author. The experiments were designed to measure the sea surface elevation and the onshore particle velocities by means of capacitance wave gauges and electromagnetic flowmeters, respectively. The experiments were conducted at a variety of beaches in order to include wave types of spilling, plunging, and collapsing forms. The characteristics of the breaking wave forms are a function of the offshore wave spectrum and the nearshore bottom slope and topography, where the increasing beach slope increases the rapidity of the breaking of the waves.

Empirical distributions were obtained for the periods, wave heights, and maximum onshore particle velocities, for waves which had been defined by the zero-up-cross method. Each of these distributions was compared with the Rayleigh probability density function (PDF). Joint PDFs of periods and wave heights, maximum velocities and wave heights, and periods and maximum velocities were calculated. 



\section{HISTORICAL BACKGROUND}

A. QUALITATIVE DESCRIPTIONT

Thornton et al. (1976) have described a number of observed universal similarities for the various types of breakers occurring on different beaches. Normally there is a quick drawdown of water just before the breaker arrives, followed by a steep, nearly vertical leading edge. Miller (1976) suggests that subsequent to the development of the leading vertical edge, a jet forms at the crest. This jet progressively extends itself forward and down until it unites with the forward slope of the breaking wave, resulting in the formation of a vortex with a circulation around a cavity. When the tip of the "jet" touches the forward slope of the breaking wave, the resulting force forms a second weaker vortex in front of the first one. In this manner, a series of vortices yields a series of large, single pulse eddies, which contribute to the rapid decay of the wave during breaking. It has been found that the magnitudes of breaker vortices are generally correlated with a gradation from plunging to spilling breakers.

Thomton et al. (1.976) have observed a sloping profile toward the trailing edge of the wave. Secondary waves are frequently noted on the trailing edge both on the analog strip charts, Figure 1 , and by visual observations in the field. The secondary waves have been observed to grow during 



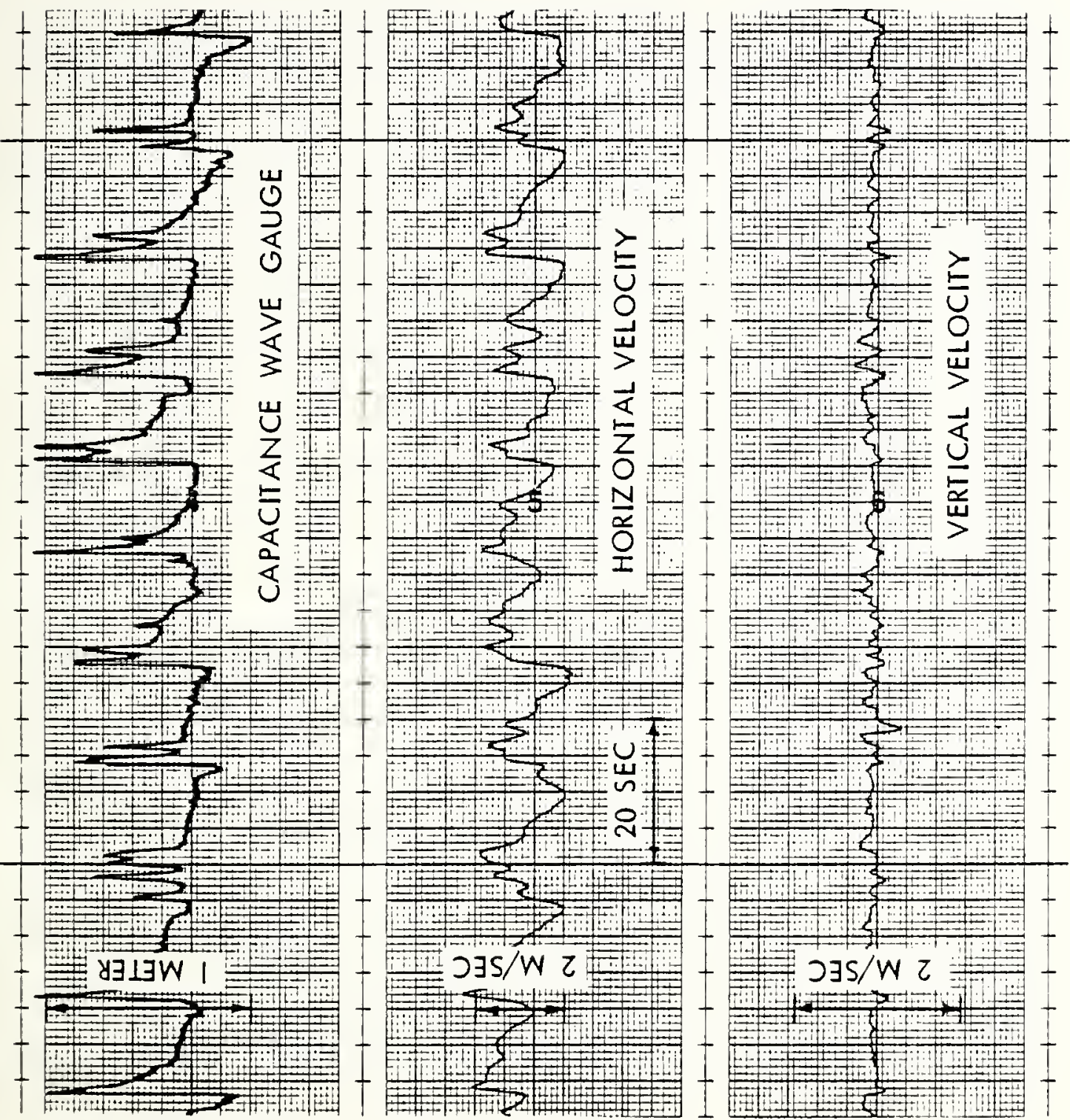

Figure 1. Strip Chart Record of Sea Surface Elevations and Particle Velocities. 

the shoaling process, especially just prior to breaking when the primary waves are steepening significantly. The secondary waves are a result of the transfer of energy from the primary wave frequency to harmonics, and help maintain the potential energy across the surf zone.

Gallagher (1971) has photographed secondary wave formation occurring across reefs. He suggests that the secondary waves are brought about by a response to vertical acceleration near the front of a broken or breaking swell. When the amplitude and surface curvature of a shallow water wave exceed certain values, the non-linearities of the vertical accelerations bring soliton wave forms into being.

Figure 1 shows that the maximum particle velocity occurs near the time of maximum surface elevation. It can also be noted in Figure 1 that there are secondary velocity maxima which correlate with the secondary surface elevation maxima. The secondary velocity peal:s also are a result of the nonlinearity associated with the breaking wave.

B. EITERY DENSITY SPECTRA OF BREAKIITG WAVES

In order to better understand the PDFs as determined in this study, the energy density spectra measured by Galvin (1975) and 01sen (1977) were reviewed. The energy density spectrum is proportional to potential wave energy within a frequency band. The energy density spectrum, $G_{X}(f)$, indicates how the variance, $\sigma_{\mathrm{x}}{ }^{2}$, is distributed over frequencies, $\mathrm{f}$, where 



$$
\sigma_{x}^{2}=\int_{0}^{\infty} G_{x}(f) d f
$$

(Kinsman, 1965)。

The energy density spectra, as estimated from the sea surface elevation records, were used to find the frequency of peak density and the occurrence of harmonics. The power spectra that were measured by Galvin showed a peak density over the frequency range of 0.061 to $0.092 \mathrm{~Hz}$ (16.4 to 10.9 sec). First, second and third harmonics can be observed as shown in the spectra of surface elevation and horizontal velocities for 4 March 1975. Additionally, subharmonics were observed at 0.011 and $0.922 \mathrm{~Hz}$ in the velocity spectra. Galvin (1975) has suggested that the observed low frequency sub-harmonic peaks may be due to edge waves in the surf zone.

Thomton et a1. (1976) note that the appearance of strong harmonics could be real due to secondary waves or artificial due to Fourier analysis of a peaked wave form. It is noted that secondary maxima of $n$ are apparent in the strip chart record shown in Figure 1 . It is felt that the secondary spectral peaks are real since secondary waves appear on the strip charts.

C. PROBABIIITY DENSITY FUNCTIONS OF PERIODS AITD HEIGHTS Studies of the PDFs of period, height, and wave lengths have been conducted over the last 20 years. The majority 



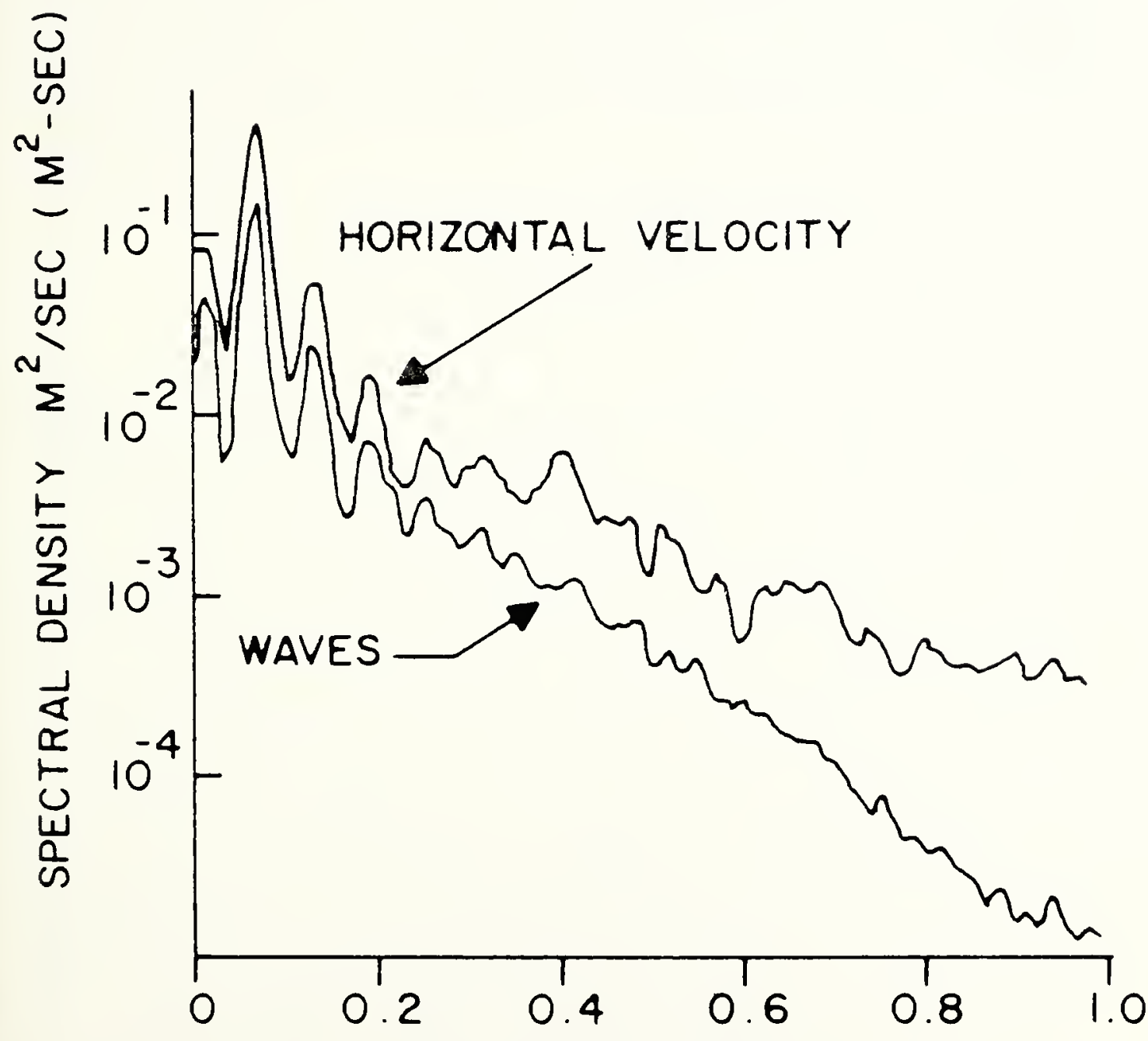

\section{FREQUENCY $(\mathrm{HZ})$}

Figure 2. Energy Density Spectra of $n$ and v, 4 March 1975. 

of these studies have been mainly concerned with theoretical or deep water aspects of the problem.

The theoretical distribution of wave amplitudes for a narrow-banded Gaussian surface elevation in deep water, was shown by Longuet-Higgins (1952) to be a Rayleigh distribution. Tayfun (1977), in studying the transformation of deep water waves to shallow water waves, showed that the Rayleigh distribution for wave amplitude was generally applicable to all bandwidths. Using the assumption that the wave height is twice the wave amplitude, the wave height PDF is then represented by:

$$
\mathrm{P}(\mathrm{H}) \mathrm{dH}=\frac{\mathrm{H}}{4 \sigma} \exp \left[\frac{-\mathrm{H}^{2}}{8 \sigma}\right] \mathrm{dH}
$$

where $\sigma$ is the variance of the surface elevation. Using pressure records in the Gulf of Mexico, Longuet-Higgins (1975) observed that the Rayleigh distribution fit the observed distribution reasonably well. He found that there is a slight excess of waves with heights near the middle of the range and a deficit at the two extremes. Since much of the high frequency portions of the wave records are filtered out by the pressure transducer, Longuet-Higgins (1975) suggests that the narrow-band approximation may not be as applicable for the unfiltered records. In shallow water with much steeper waves, the distribution can again be expected to be less applicable due to the non-linearities which become increasingly important. 

Since the statistics of $\mathrm{H}$ and $\mathrm{T}$ for a broad-banded spectrum were still somewhat unclear, Goda (1970) simulated wave profiles using an infinite series where the amplitudes were specified by various theoretical spectra and the phase was random with a computer. He then examined the simulated wave records for surface elevation, crest-to-trough wave . heights and zero-up-cross wave heights. He found that for the zero-up-crossing determination of wave heights, the Rayleigh distribution is a good approximation irrespective of the spectral width.

Goda (1970) suggests that the deviation of the wave height distribution from the Rayleigh type in shallow water should be considered separately from the change in the functional shape of the wave spectrum. It must be a highly nonlinear phenomenon, which requires full analysis with the theory of non-1inear wave spectra.

Bretschneider (1959) investigated the PDFs of wave heights, H, wave lengths, $L$, and wave periods, $T$. He concluded from his empirical study that in deep water wave systems, the PDFs of wave heights and lengths can be approximated by a Rayleigh distribution. Using the relationship, wave length proportional to period squared for deep water linear waves, he concluded that the PDF of periods squared is a Rayleigh PDF given by

$$
p(T)=2.7 \frac{T^{2}}{T} \exp \left[-0.675\left[\frac{T}{\bar{T}}\right]\right]^{4}
$$

where $\overline{\mathrm{T}}$ is the mean period. 

Using simulated wave data, Goda (1970) found that the crest-to-crest periods squared were generally not well approximated by the Rayleigh PDF. The mean and standard deviations of the periods by this method were found to be a function of the spectral width. He found that the periods determined by the zero-up-cross method are only in fair agreement with Bretschneider (1959). If the waves are of the type which have sharply peaked spectra, double peaked spectra, or a flat spectrum, Bretschneider's (1959) distribution was totally in disagreement with that of the simulated waves.

Contrary to Bretschneider (1959) and Goda (1970), Longuet-Higgins (1975) noted that in general the deep water wave periods were bell shaped (but not Gaussian). He defines the period PDF when calculated by the zero-up-cross method as,

$$
p(n)=\frac{1}{2\left(1+n^{2}\right)} \frac{3}{2} ; \quad n=(\tau-\langle\tau\rangle) / \nu\langle\tau\rangle
$$

where $\langle\tau\rangle$ is the mean period and $\nu$ is proportional to the spectral width where

$$
v=\left(\mu_{2} / \mu_{0}\right)^{\frac{1}{2}}(<\tau>/ 2 \pi)
$$

and $\mu_{0}$ and $\mu_{2}$ are the zero and second moments of the energy spectrum.

Koele and de Bruyn (1964), Goda (1967), and Siefert (1370) have observed that the distribution of wave heights in shallow water does not correlate well with the Rayleigh 

distribution. Kuo and Kuo (1974) have suggested that this is due to: 1) the non-linear effects of wave interactions yielding more larger waves, 2) the effect of bottom friction yielding a reduction in the low frequency components, and 3) the effects of wave breaking, which would truncate the distribution and transfer some of the kinetic energy to the high frequency components. Therefore the PDFs of wave heights with a certain intensity, may be considered to approxinate a conditional Rayleigh distribution truncated by the local breaking height.

A zero-up-cross analysis was conducted on waves measured on a reef by Black (1978), who then compared the observed distribution with the Rayleigh, truncated Rayleigh, and the Weibull distributions. He observed that the truncated Rayleigh distribution fit well for those waves in the breaker zone when the heights were depth limited. The truncated Rayleigh distribution did not fit well for those waves measured either inshore or offshore of the breaker zone. He has found that a Weibull distribution more closely approximated these measured distributions.

It would be expected that the Weibull distribution would yield the better fit. The Rayleigh distribution is a function of the variance of the data, whereas the Weibull distribution is a function of higher moments about the mean. Neither theoretical distribution adequately describes observed distributions which are multi-modal.

Black's (1973) observations of wave periods showed a distribution which was skewed to the right. This does not 

fit well with the symetrical Longuet-Higgins (1975) distribution. It was found that the period distribution more closely followed the Rayleigh distribution than the period square as proposed by Bretschneider (1959). It was found that the Weibull distribution most closely fit the empirical.PDF, but there is considerable variation in the peakedness parameter. His attempts in relating the period statistics to the position on the reef were unsuccessful. He feels that this is due to the non-linearities of the waves in shallow water.

In this thesis, the empirical data collected for breaking waves were compared with the Rayleigh distribution.

\section{JOINT PROBABILITY DENSITY FUNCTIONS}

A study of the joint PDF for wave heights, $n$, and lengths, $\lambda$, which can be viewed as heights and periods) was accomplished by Bretschneider (1959). The general form of the joint PDF for two related variables $(n, \lambda)$ is the product of the marginal PDF $(p(n))$ and the conditional PDF $\left(p_{n}(\lambda)\right)$.

$$
p(n, \lambda)=p(n) \cdot p_{\eta}(\lambda)
$$

then

$$
p(n)=\int_{0}^{\infty} p(n, \lambda) d \lambda=p(n) \int_{0}^{\infty} p_{n}(\lambda) d \lambda
$$

Assuming that the marginal PDFs are Rayleigh, Bretschneider (1959) examined the extreme cases of 0 and +1 correlation. For the case of zero correlation, the marginal 

Rayleigh PDFs are given by

$$
\begin{aligned}
& \mathrm{p}(n)=\frac{\pi}{2} n \exp \left(-\pi \eta^{2} / 4\right) ; \quad n=\mathrm{H} / \overline{\mathrm{H}} \\
& \mathrm{p}(\lambda)=\frac{\pi}{2} \lambda \exp \left(-\pi \lambda^{2} / 4\right) ; \lambda=\mathrm{L} / \overline{\mathrm{L}}
\end{aligned}
$$

For zero correlation, i.e. total independence (Figure 3), the joint PDF is,

$$
p(n, \lambda)=p(n) \cdot p(\lambda)
$$

so that the joint PDF of heights and lengths is given as,

$$
p(n, \lambda)=\frac{\pi^{2}}{4} n \exp \left(-\pi n^{2} / 4\right) \cdot \lambda \exp \left(-\pi \lambda^{2} / 4\right)
$$

In terms of heights and periods, equation 15 is,

$$
p(\eta, \tau)=1.35 \pi \exp \left(-\pi n^{2} / 4\right) \cdot \tau^{3} \exp \left(-0.675 \tau^{4}\right)
$$

where $\tau=\mathrm{T} / \overrightarrow{\mathrm{T}}$.

For the case of total dependence, the correlation coefficient is equal to one. For a correlation coefficient of one, all data points on a plot of joint Rayleigh PDFs fall on a 45 degree straight line passing through the origin, $\eta=\lambda=0$. Assuming that a joint Rayleigh distribution is applicable, the following relation applies:

$$
p(n, \lambda)=\frac{\pi}{2} n \exp \left(-\pi n^{2} / 4\right) \cdot \frac{\pi}{2} \lambda \exp \left(-\pi \lambda^{2} / 4\right)
$$

which is plotted in Figure 3. 



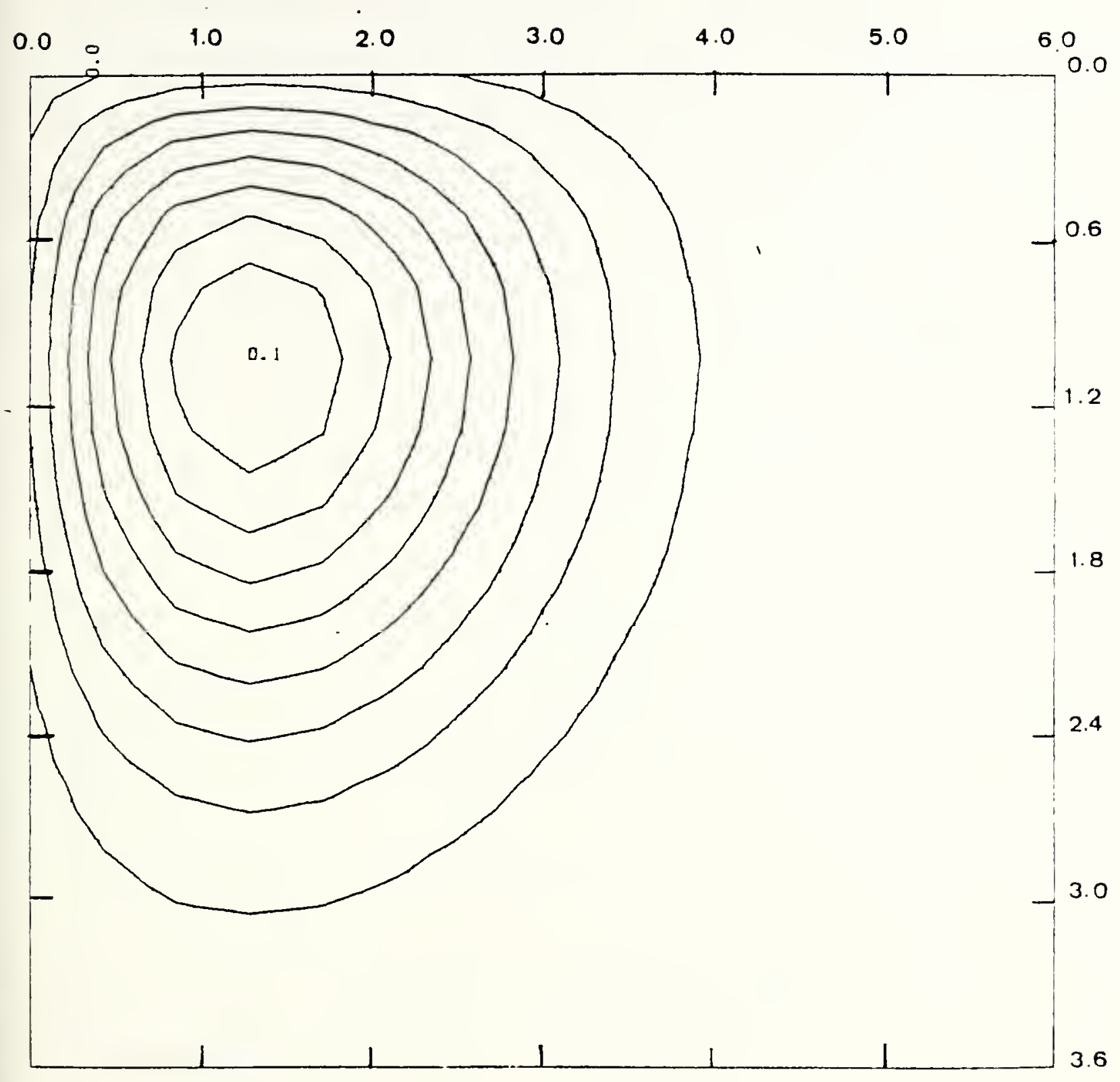

Figure 3. Statistically Independent Joint Rayleigh PDF. 

Collins (1970) studied the PDFs of breaking waves derived from deep water waves having a joint Rayleigh distribution of heights, lengths and angles. He assumed that $\mathrm{H}=\mathrm{\gamma d}$, where $\mathrm{I}$ is the breaker height, $\mathrm{d}$ is the breaker depth, and $\gamma$ is the breaking criterion assumed. The limiting factor of waves breaking in the surf zone yields a distribution better approximated by a truncated Rayleigh distribution. As expected, he found that the longest deep water waves were associated with the largest breaking waves.

Collins (1970) concluded from the study of the joint PDFs of wave heights and lengths, that the effect of deep water angle of approach is relatively minor for breaking waves. The breaking wave steepness was found to be very sensitive to the choice of breaking criteria.

A theoretical expression for the joint distribution of wave periods and amplitudes was derived by Longuet-Higgins (1975) for a narrow frequency spectrum

$$
\mathrm{p}(\xi, n)=\frac{\xi^{2}}{(2 \pi)^{\frac{1}{2}}} \exp \left(-\xi^{2}\left(1+\eta^{2}\right) / 2\right)
$$

where $\xi$ and $\eta$ are the normalized amplitudes and periods as defined by,

$$
\xi=a / \mu_{0}^{\frac{1}{2}}
$$

and

$$
\eta=(\tau-\langle\tau\rangle) / v\langle\tau\rangle
$$

where $v$ is defined in equation 5. The wave amplitude 

is a , Ho is the zeroth moment of the energy spectrum, and $\langle\tau\rangle$ is the mean wave period. Longuet-Higgins (1975) compared this theoretical distribution of ocean waves to that of the deep water data obtained by Bretschneider (1959) and found good agreement.

Chakrabarti and Cooley (1977) compared the theoretical joint distribution of Longuet-Higgins (1975) with wave data recorded during a 1961 storm in the North Atlantic. The spectrum of these waves did not fall in the category of narrow-band. Through the comparison, it was found that there vas a considerable agreement at the higher wave heights, but a definite trend away from the theoretical curve at the lower wave heights. 



\section{EXPERIMENT}

\section{A. EXPERIMENTAL SITES}

Three different Califomia experimental sites were used to obtain data on the three types of breaking waves--plunging, spilling, and collapsing. During the period 4 March to 10 March 1975, plunging and spilling waves were measured by Galvin (1975) on Del Monte Beach, Monterey, Califomia. This locale was chosen because the waves are highly refracted and directionally filtered, yielding narrowbanded swell offshore which impinges almost perpendicularly on the beach.

On 29 May 1975 Galvin (1975) conducted a second experiment on the Carmel River Beach, which is located approxinateIy five miles south of Monterey, California. This area is in an embayment, where the waves are again highly refracted and directionally filtered. The beach at this site is very steep resulting in plunging and often collapsing and surging breakers. Due to the steepness of the beach and the rapidity of breaking of the shoaling waves, reflected waves are found to be present.

Spilling breakers on a gently sloping beach were measured in March 1977 at Torrey Pines Beach, a site just north of La Jolla, Califomia (Olsen, 1977).

On 3 and 9 March 1978 data were collected by this author on Del Monte Beach, Monterey, California. On the first day of the experiment, very narrowbanded swell was observed 

breaking on the shore, mainly of the plunging type. A storm arrived late on 8 March and continued through 9 March. Winds of approximately 15 knots yielded a very confused sea. Breakers were of both the spilling and plunging type and were observed to break at various small angles relative to the beach. Sea surface elevations and velocities were collected for approximately three hours on each of these days on both the flowing and ebbing sides of high tide.

\section{B. INSTRLNTENTS}

Capacitance type gauges were used to measure the change in the sea surface elevation as explained by Thomton et al. (1976). The wave gauges were constructed of $3 / 8$ inch polypropylene covered stainless steel rod. Cálibration was accomplished in the laboratory statically by lowering the wave gauge into a deep water tank. Depth of immersion was then plotted against volts.

The velocity of the water particles was measured with Marsh-McBirney Model 721 and 722 Electromagnetic Current meters. These flowmeters work on Faraday's principle of electromagnetic induction and are capable of recording the particle velocities in orthogonal directions in a plane. The meters were dynamically calibrated in the laboratory. Calibration was accomplished by oscillating the current meters in a water tank with a prescribed motion simulating the flow conditions which would be expected to be found in the surf zone. The flowmeter voltage output was found to be linear in the velocity ranges found in the breakers. 

All instruments were placed on towers in the surf zone at low tide at the expected point of breaking of the waves for the subsequent high tide. Each tower held a capacitance wave gauge and an electromagnetic flowmeter. The flowmeter was placed below the wave gauge, approximately $0.5 \mathrm{~m}$ from the bottom, to insure constant submergence. Data were collected within an hour or two on both the ebb and flow sides of high tide. Analog recordings were made on both a strip chart and magnetic tape.

\section{DATA ANALYSIS}

All signals were digitized from their analog form by means of a Vidar Corporation 32-channel digital data acquisition system. The digitized data were then processed on an IBM $360 / 67$ computer. Record lengths of approximately 30 minutes from each data set were analyzed. Specific details of the analysis can be found in Appendix A.

The data were edited by excluding any value greater than six standard deviations from the mean and replacing that value with the previous value. The values were then linearly detrended to exclude the effects of the rising or falling tides. The mean and variance of sea surface elevations were calculated for each record as well as the mean and variance of the heights, periods and maximum velocities al1 of which are defined on page 27.

It was desired to only examine the sea-swell band of frequencies lying between $0.03-1.0 \mathrm{~Hz}$ (30 sec-1 sec). Hence, the data were passed through both a high and low pass digital filter. 

The high pass filter had a cut-off frequency of $0.03 \mathrm{iz}$ $(30 \mathrm{sec})$. The high pass filter used a Fast Fourier Transform (FFT) algorithm to obtain the Fourier spectrum of the entire 30 minute record. The Fourier coefficients corresponding to 0-0.03 $\mathrm{Hz}$ were then used to synthesize a low frequency time series which was subtracted from the wave record.

The low pass filter was a 25 weight inverse transform filter (Davidson, 1970), as shown in Figure 4. A cut-off frequency of $1.2 \mathrm{~Hz}$ was used with a terminal frequency of $1.8 \mathrm{~Hz}$.

Wave heights were determined from the surface elevation record by means of the zero-up-cross method. The zero-upcross technique defines a wave period as the interval between adjacent upcrosses. The maximum and minimum of the surface elevation within the interval defines the crest and trough of a wave. Maximum onshore particle velocities were calculated from the flowmeter records. Maximum onshore velocity was defined as the maximum velocity amplitude occurring between successive zero upcrossings as defined by the sea surface elevation record. Joint PDFs of wave height and period, wave height and maximum velocity, and maximum velocity and period were calculated from the analyses.

Heights and maximum velocities were normalized by dividing by their respective standard deviations. The periods were normalized by dividing by their mean period. The notation used is

$$
\begin{aligned}
& \mathrm{H}=\mathrm{H}^{\prime} / \sigma_{\mathrm{n}} \\
& \mathrm{V}=\mathrm{V}^{\prime} / \sigma_{\mathrm{V}} \\
& \mathrm{T}=\mathrm{T}^{\prime} / \overline{\mathrm{T}}
\end{aligned}
$$





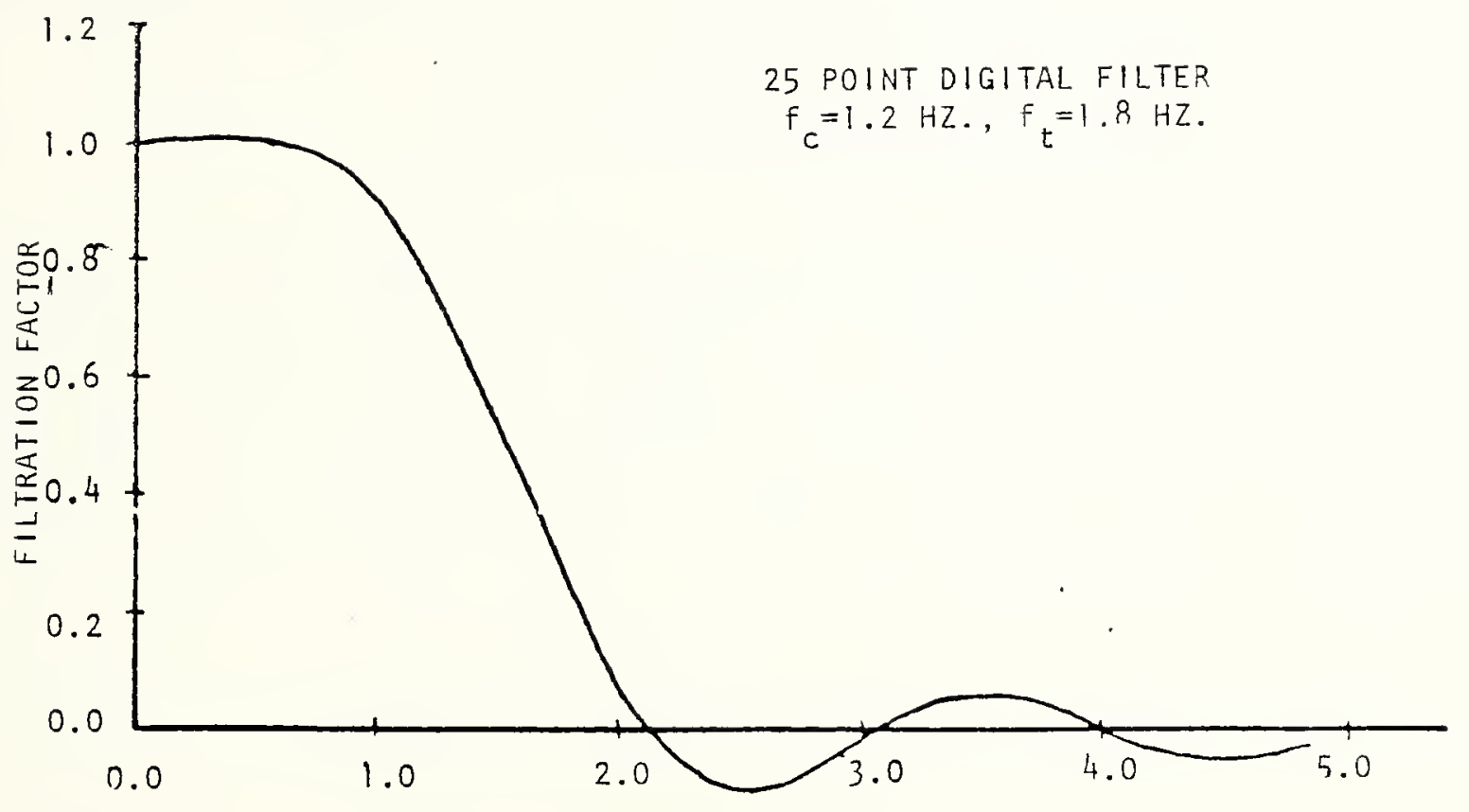

FREQUENCY (HZ.)

Figure 4. Low Pass Digital Filter. 

where heights $\left(\mathrm{H}^{\prime}\right)$, maximum velocities $\left(\mathrm{V}^{\prime}\right)$, and periods $\left(T^{\prime}\right)$ are the values as determined by the zero-up-cross method. $\overline{\mathrm{T}}$ is the mean period, and $\sigma_{\eta}$ and $\sigma_{\mathrm{v}}$ are the standard deviations of the surface elevations and particle velocities respectively. Histograms were calculated for the normalized heights, periods, and maximum velocities. The histograms were transformed into PDFs by dividing the number of value over an interval by the total number of values in the array and by dividing by the interval width. The mathematical expression for the exact PDF is

$$
p(x)=\lim _{x \rightarrow 0} \frac{1}{\Delta x}\left\{\lim _{\mathbb{N} \rightarrow \infty}\left[\frac{\mathbb{N}}{N}\right]\right\}
$$

where $\mathrm{N}_{\mathrm{X}}$ is the number of times the variable occupies an interval, $\mathbb{N}$ is the total number in the record observed, $\Delta x$ is the interval width and $p(x)$ is the PDF. A restriction on the probability density is that

$$
\int_{0}^{-\infty} p(x) d x=1 .
$$

Joint probability density functions of periods versus heights, velocities versus heights and periods versus velocities were calculated in a similar fashion. A 15 by 15 grid was used to determine the frequency of values which simultaneously fill each joint interval. Mathematically the probability that the arrays $x$ and $y$ simultaneously assume values within the range $(x, x+\Delta x),(y, y+\Delta y)$ may be 

obtained by taking the ratio of the total number of times of each occurrence within a bin, $\mathbb{N}_{x y}$, and the total number of observations, $N$. The exact probability density is approached as the number of observations approaches infinity the interval widths approach zero. The joint PDF can be defined as:

$$
p(x, y)=\lim _{\substack{x \rightarrow \infty \\ y \rightarrow \infty}} \frac{1}{\Delta x \Delta y}\left\{\stackrel{\lim }{N \rightarrow \infty}\left[\frac{\bar{N}}{\frac{x y}{N T}}\right]-\right\}
$$

with the restriction

$$
\int_{0}^{+\infty} \int_{0}^{+\infty} p(x, y) d x d y=1
$$

The energy density spectrum (power spectrum) was obtained by means of a Fast Fourier Transform (FFT) algorithm. The energy density spectrum tells how the variance is distributed with respect to frequency.

The spectral width parameter was calculated using the equation:

$$
\varepsilon=\sqrt{\frac{\mathrm{m}_{0} \mathrm{~m}_{4}-\mathrm{m}_{2}^{2}}{\mathrm{~m}_{0} \mathrm{~m}_{4}}}
$$

where $\mathrm{m}_{0}, \mathrm{rn}_{2}$, and $\mathrm{m}_{4}$ are the spectral moments (Cartwright and Longuet-Higgins, 1956). For $\varepsilon=0$ the waves have only one frequency and the energy spectrum would be represented by a spike. As $\varepsilon \rightarrow 1$ the sea surface can be described as a broadband process for which the distribution would be Gaussian and the spectrum would approach a horizontal line. Swell 

can therefore be described as a narrow-band process and seas as broad-band. Due to the appearance of secondary waves, a narrow-banded deepwater spectrum of waves broadens in the surf region.

The correlation coefficients of the joint values were calculated to obtain a measure of the amount of linear relationship of random pairs of values of periods and heights, velocities and heights, and periods and velocities,

$$
r(x, y)=\frac{1}{N-1} \sum_{i=1}^{N} \frac{\left(x_{i}-\bar{x}\right)\left(y_{i}-\bar{y}\right)}{\sigma_{x} \sigma_{x}}
$$

where $\bar{x}$ and $\bar{y}$ are the sample means, $x_{i}$ and $y_{i}$ are the sample stancard deviations. 



\section{DISCUSSION}

Miller (1976) concluded that breaker shapes form a continuous gradation of shapes from spilling to plunging. Each breaker type undergoes the same processes, but differs only in the magnitude of the vortices generated. The probability density functions appear to show a similar gradation. Two simplified cases, for spilling and plunging, were chosen to represent extreme examples and are used for all discussions. The 4 March 1975 data most simply represent the plunging case and the 16 March 1977 data represent the spilling case. The results for all data are given in Appendix $C$.

In both examples for spilling and plunging breakers, the offshore waves appeared as narrow band swe11. A spectral analysis of the surface elevation records in the surf zone yielded spectral width parameters ranging from 0.94-0.97 (see Appendix A), suggesting a broad band spectrum in the surf zone. The broad spectral width can be attributed to the non-linear wave-wave interactions yielding harmonics in the breaking zone.

In order to determine the origin of the large spectral width parameter, $\varepsilon$ was calculated in the ranges of $0-0.25$ $\mathrm{Hz}, 0-0.50 \mathrm{~Hz}, 0-1.0 \mathrm{~Hz}$ and 0 -nyquist frequency. The analysis revealed that large values of the spectral width parameter occurred in all cases. In the case of $0-0.25 \mathrm{~Hz}$ which contains the first three harmonics, $\varepsilon$ was greater than 0.7 , 

which was the case with the smallest $\varepsilon$. It is concluded that the change from a narrow deep water spectrum to a broad-band shoaling spectrum is primarily due to generation of secondary waves at harmonic frequencies.

\section{A. PERIOD PROBABILITY DENSITY FUNCTIONS}

Bretschneider (1959) made the assumption that the wave lengths were Rayleigh distributed; using this assumption and the linear wave theory relationship

$$
L=\frac{g}{2 \pi} T^{2}
$$

the wave periods squared would be Rayleigh distributed in deep water. Bretschneider's analysis can be extended to the shallow water case using the shallow water approximation for wave length

$$
L=\sqrt{g h} T
$$

Assuming the wave lengths are Rayleigh distributed, the periods in shallow water would be expected to be Rayleigh distributed.

The period PDFs for plunging and spilling examples are shown in Figures 5 and 6 respectively. The Rayleigh PDF has been superimposed on the period PDFs for comparison. The formulas used for the Rayleigh PDF for various parameter transformations are given in Appendix A. In both the spil1ing and plunging wave examples, it is noted that the period PDEs only loosely follow the Rayleigh PDF. The Rayleigh PDF 



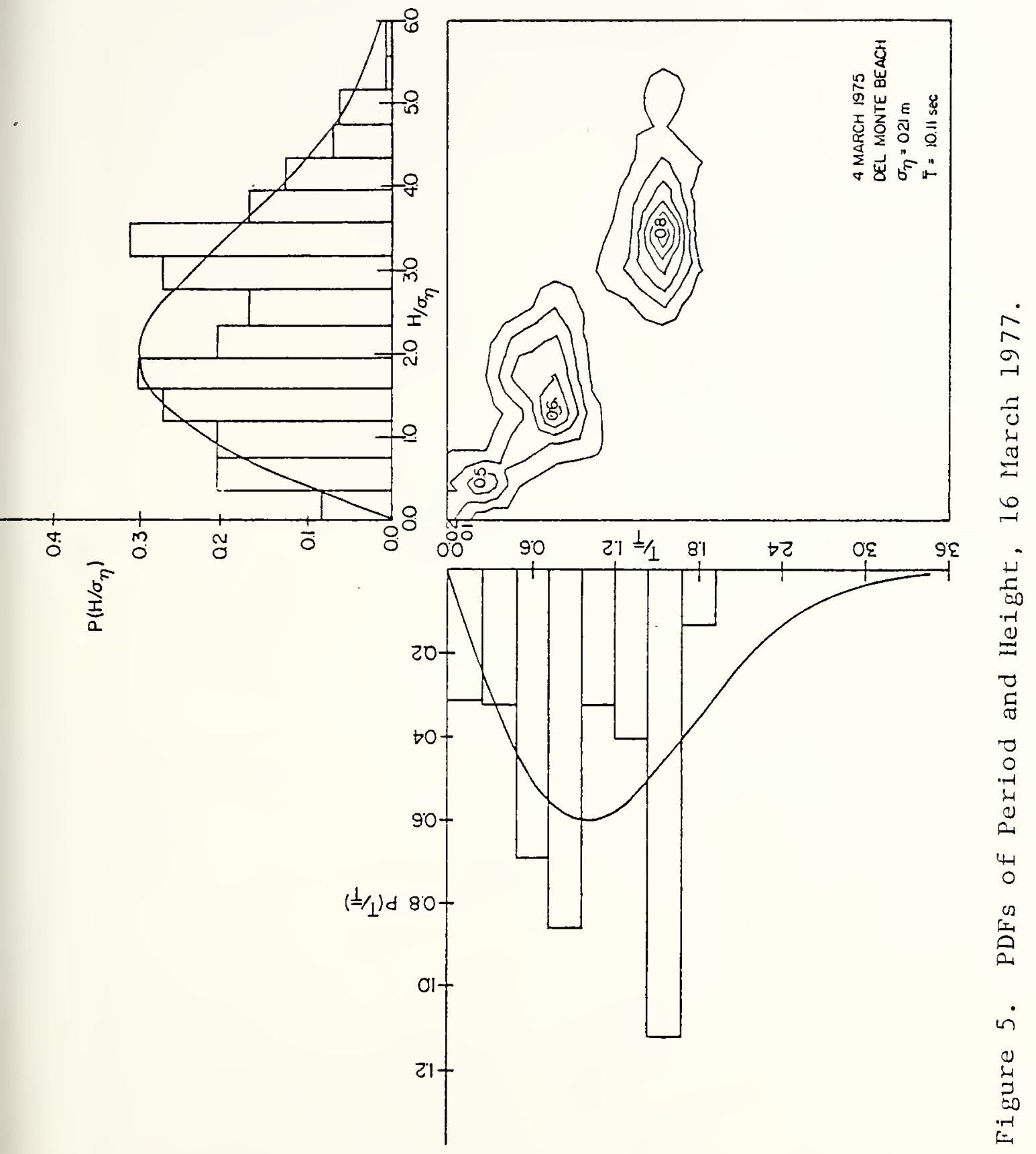





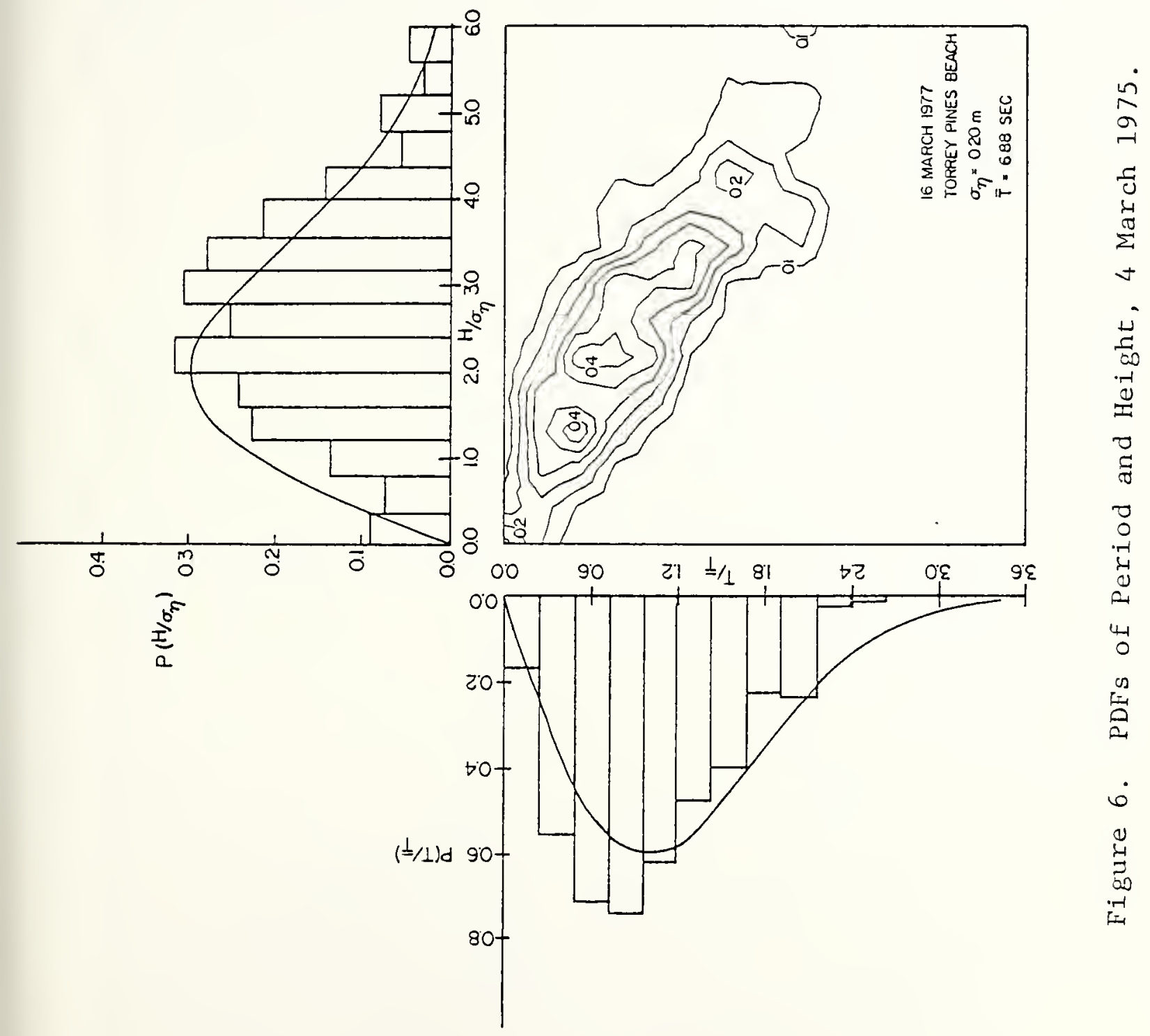



overpredicts the wave periods greater than the Rayleigh mode value, and underpredicts the observed periods less than the peak Rayleigh value. The truncation of the long period waves is probably due to the larger period waves breaking farther offshore and then reforming to be recorded by the stationary wave gauge as higher frequency waves.

The spilling example for 16 March 1977, shown in Figure 5, has the mode lying close to the maximum of the superimposed Rayleigh PDF. The peak of the breaking wave distribution is located at the first harmonic of the offshore wave period, which is attributed to the secondary waves. A peak corresponding to the peak offshore wave period is absent.

The plunging waves, as represented by the 4 March 1975 record in Figure 5, are multimodal. Since the Gaussian, GramCharlier, Rayleigh and Weibull PDFs are unimodal, none of the theoretical PDFs will adequately describe multi-modal PDFs for this particular plunging surf condition.

Two strong peaks are found to occur in the plunging breaker period PDF. The longer period is found to correlate well with peak period of the wave spectrum. The shorter wave period appears at approximately the first harmonic. Since the center period of the bin is used to represent the interval, the magnitude of the peaks and the proximity to harmonics as represented by the labels is a function of the interval width and the interval cutoffs. A 30 bin PDF was calculated for better resolution to determine if the peaks were harmonics and Figure 7 shows that they are. 



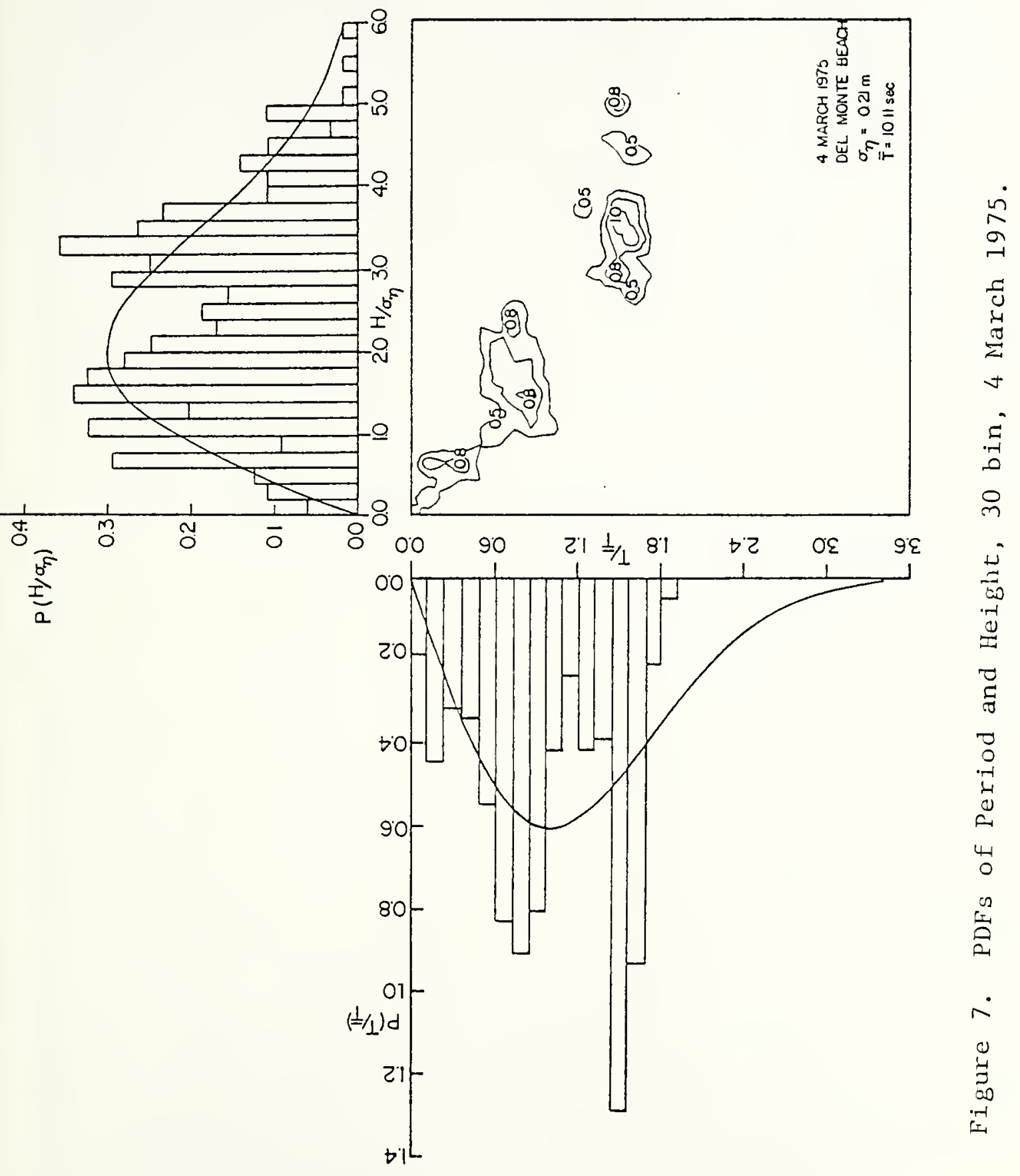



The waves periods as determined by a zero-up-cross of the surface elevation record for spilling conditions yields a poor indication of the peak of the energy spectrum which corresponds to the mean offshore wave period. In the spilling breaker case, the mean period corresponded to the first harmonic of peak in the energy spectrum. For the plunging breakers, the mean period corresponded to a valley in the period PDF between the primary and first harmonic periods. The appearance of strong peaks at one half the offshore wave period is indicative of the importance of non-linearities in the form of secondary waves in the surf zone.

\section{B. HEIGHT PROBABILITY DENSITY FUNCTIONS}

Wave height PDFs for the plunging and spilling wave examples are shown plotted against the theoretical Rayleigh $\mathrm{PDF}$ in Figures 5 and 6 . The height PDF for spilling waves is not as easily described as the period PDF. The height PDF is loosely described by the Rayleigh PDF. The major height peak is centered at 2.2. The Rayleigh PDF overestimates the density of the small wave observations and tends to underestimate the density of the large waves. The heights are truncated at approximately six standard deviations. Since the wave gauge is stationary and therefore the depth of the water is essentially fixed, this truncation occurs due to the breaking of the large waves seaward of the wave gauge. The calculated mean height value on 16 March 1977 lies at 2.7, which actually corresponds to a dip in the PDF relative to the peak intervals on either side. 

The mean height observed in the 4 March 1975 plunging breaker PDF was calculated to be at 2.4. The observed PDF is found to be strongly bimodal with peaks at 1.8 and 3.4 . The strong bimodality is attributed to the very narrow band incident wave system and the generation of secondary waves at the first harmonic.

C. JOINT PROBABILITY DENSITY FUNCTIONS ( $T$ vS $H$ )

The joint PDF of periods and heights for the plunging and spilling examples are contoured in Figures 5 and 6 ; the distributions for all cases are found in Appendix C.

It is noted that the longest wave periods are associated with the greatest wave heights suggesting strong correlation between periods and heights. The correlation coefficient was calculated for all cases and varied between 0.60 and 0.80 . Bretschneider (1959) examined the two special cases of joint Rayleigh distributions with correlations of 0 and +1 . Perfect correlation between two variables would result in correlation coefficient of 1.0 and a straight line in the joint PDF.

The joint Rayleigh PDF for the case of a correlation coefficient of zero is plotted in Figure 3. Zero correlation, or statistical independence, results in the joint PDF being spread out as compared with the straight line for perfect correlation. The amount of spread is a measure of the reduction in correlation.

Figure 5 is an example of $\mathrm{p}(\mathrm{H}, \mathrm{T})$ for plunging breakers and shows two regions of high density. The bimodality of 

$p(H)$ and $p(T)$ are reflected in the $p(H, T)$. The maximum peak period, which corresponds to the peak in the wave spectrum, is highly correlated with the primary peak of wave heights. The second high density region corresponds to the first harmonic of the primary wave period. The joint PDF suggests strong wave-wave interactions in a plunging wave system resulting in energy transfer to harmonics.

Two distinct contour groups are no longer apparent in Figure 6 for the spilling case, but rather one long contour is found. Since the height PDF and the period PDF are only weakly bimodal, it follows that a single contour group should be found. The area of maximun joint density is found to be associated with the first harmonic of the offshore wave period, and the mode of the observed breaker heights. Greater density was found at short periods and heights for all records than predicted by the Rayleigh PDF. A high frequency wave riding on a long period wave causes an additional zero crossing as the longer wave passes through zero. Most previous comparisons of heights or periods of waves have been done using pressure sensors which greatly filter the high frequencies due to hydrodynamic attenuation. Capacitance wave staffs and electromagnetic flowmeters have good response times and thus measure high frequencies. Therefore, even though the data were filtered at $1 \mathrm{~Hz}$, all records showed peaks at the shortest periods and heights. 



\section{VELOCITY PROBABILITY DENSITY FUNCTIONS}

The velocity PDFs were calculated as the maximum onshore velocities within the period segments determined by the zeroup-crosses of the surface elevation record as shown in Figures 8 and 9 . Using this technique can result in both positive and negative maximas for onshore particle velocities (i.e., $d^{2} v / d t<0$ ).

The velocity PDFs for spilling breakers and plunging breakers are shown in Figures 8 and 9 . The theoretical Rayleigh PDF is superimposed on the same graphs for comparison. It is apparent that neither the spilling or plunging case is adequately described by the Rayleigh PDF. The velocity PDF for spilling breakers appears to be symmetrical, with the mode value falling at the bin with center velocity of 1.5. There also appears to be a small peak value at 0.3 . When compared with the plunging case, it is found that the peaks occur at the same normalized velocities. The plunging wave PDF is bimodal and has relatively few occurrences of negative onshore velocities.

\section{E. JOINT PROBABILITY DENSITY FUNCTIONS ( $\mathrm{V}$ VS $\mathrm{H}$ )}

The joint probability distributions of velocities and heights are shown in Figures 8 and 9 . The results show high correlation between velocities and heights. The high positive correlation suggests that the larger maximum onshore velocities are correlated with the larger wave heights.

Figure 8 shows the plunging breaker case. Two peak areas are found to occur in the joint $\mathrm{PDF}$ which reflects the 



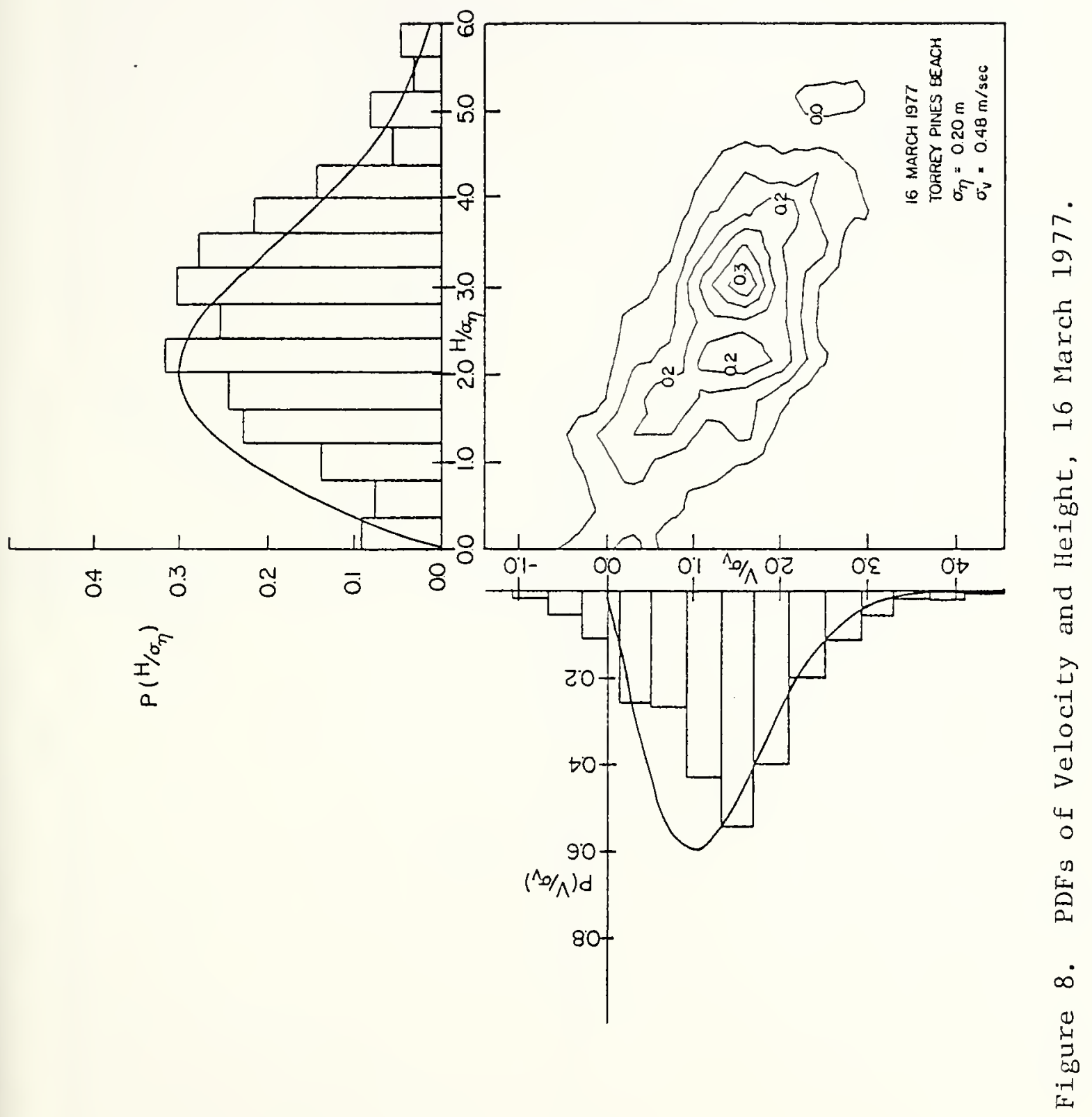





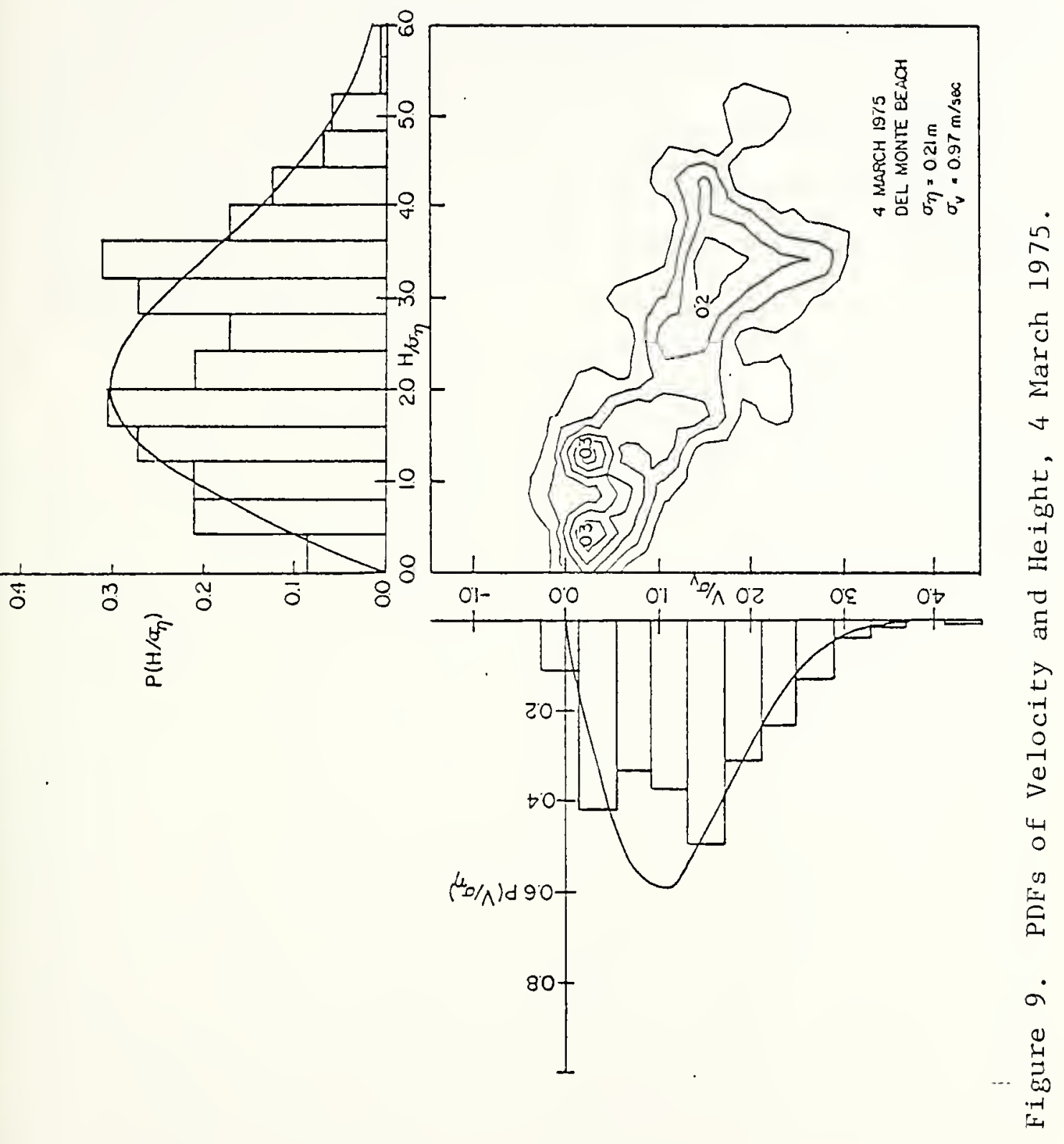



bimodality of the individual PDFs. The joint PDF for the plunging waves suggests a highly correlated case (0.68) in which the largest onshore velocities occur due to waves of greatest height.

The spilling case as shown in Figure 9 also shows high correlation (0.70). For this example, there is only one major peak which corresponds to the individual PDFs which are essentially unimodal. The peak area of the joint PDF has been shifted toward higher waves and greater velocities than the plunging case.

F. JOINT PROBABILITY DENSITY FUNCTIONS ( $T$ VS $V$ )

Figures 10 and 11 show joint PDFs of periods and velocities in which the periods were determined from the zero-upcrosses of the wave gauge record and the coincident maximum onshore velocities are detemined from the flowmeter record. The results are similar to the joint PDF of period and heights. Spilling waves, as contoured in Figure 11, show one main contour group. The maximum spilling probability is found at the intersection of period 0.84 and velocity 1.5 . The plunging waves as found in Figure 10 reveal two contour peaks. One large contour group is associated with the point representing the offshore period 1.56 and a velocity of 1.5 . The second large contour is a function of the first harmonic wave period of 0.84 and a velocity of 0.3 .

The negative values of the maximum velocity indicate that, during a wave period defined by the zero-up-crosses of the surface elevation, the maximum velocity can be negative. 



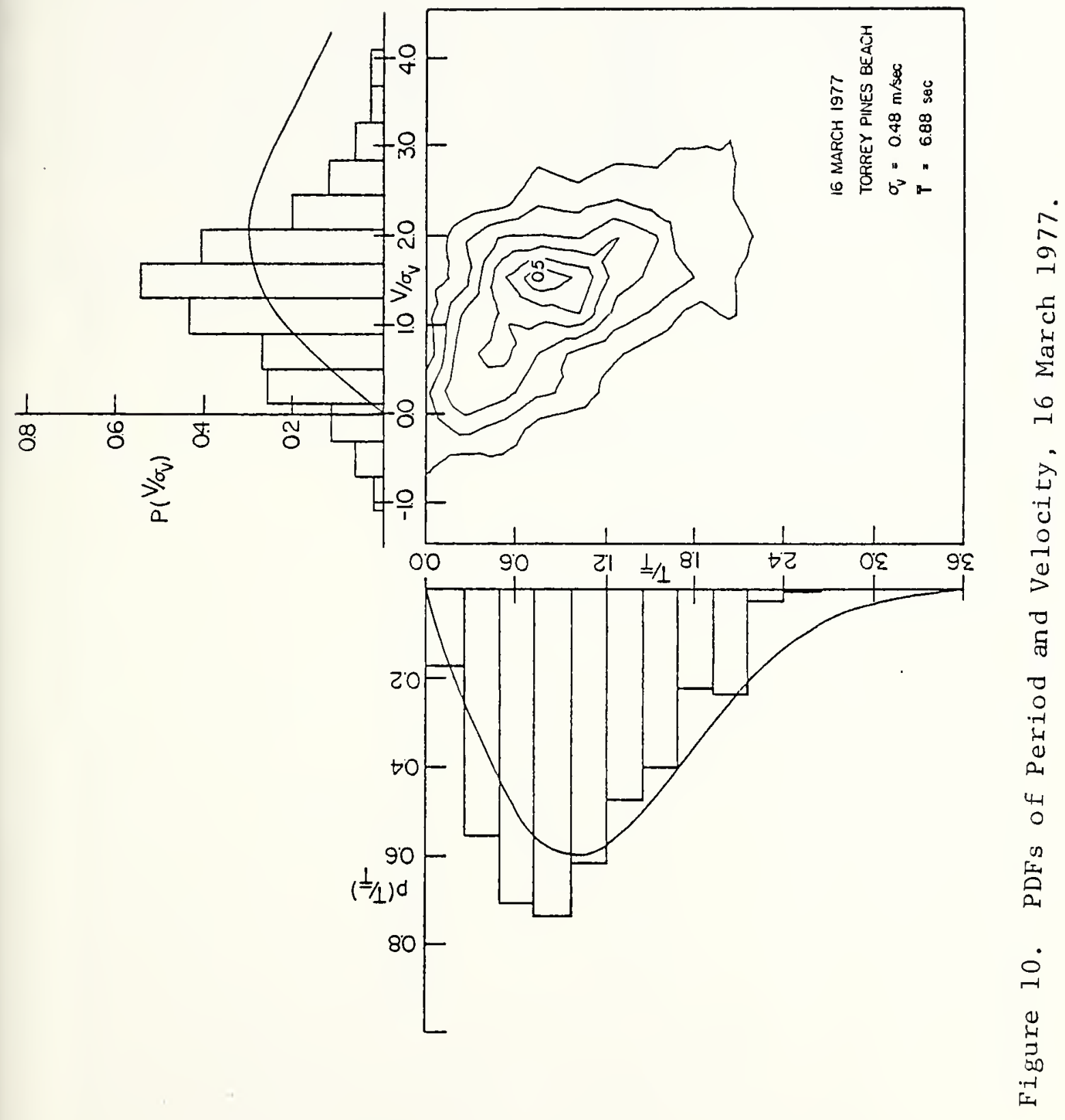





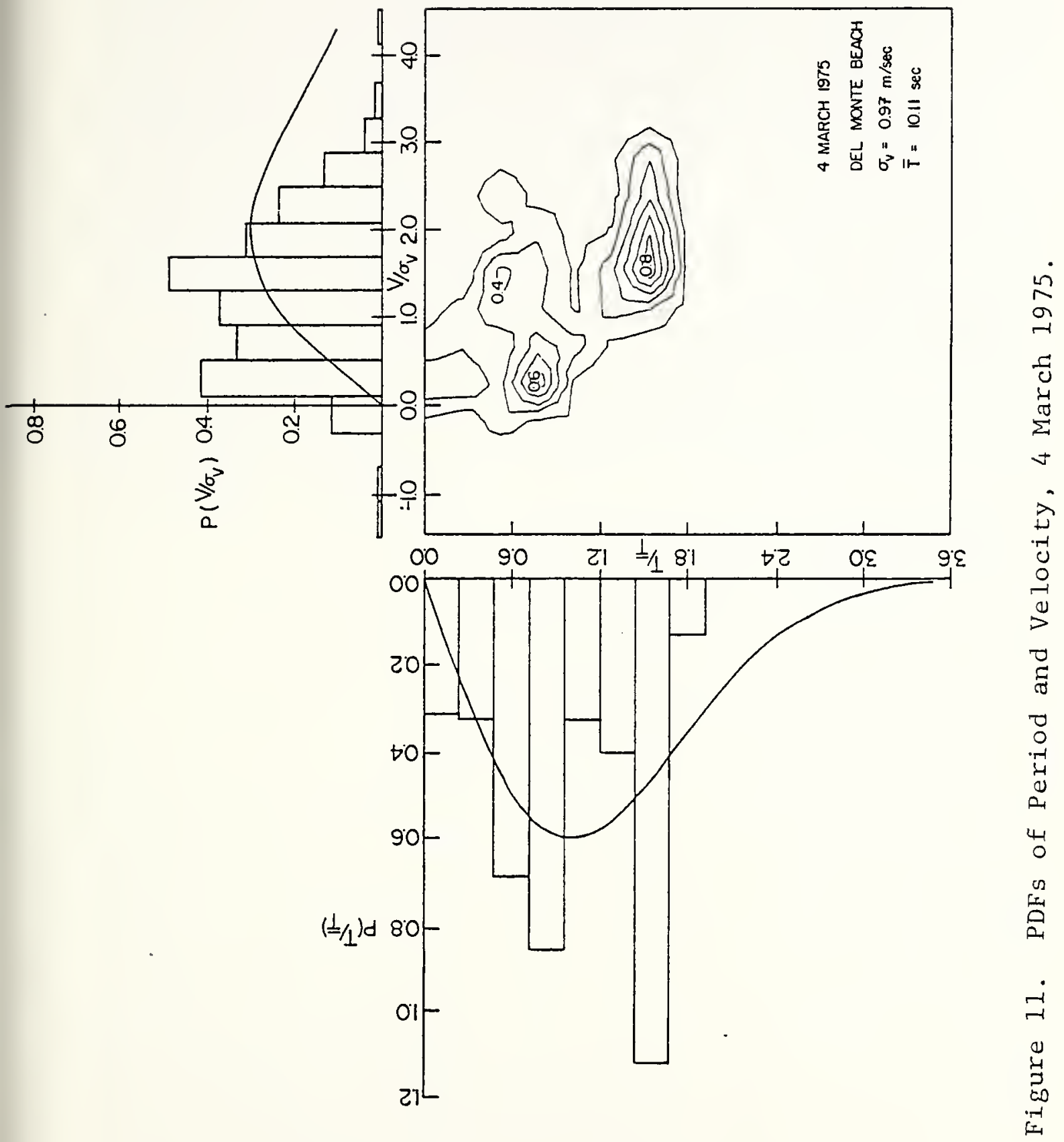



The joint PDF of wave height and velocity shows that the negative velocities are associated with the low wave heights. The joint PDF of velocity and period shows that small negative velocities are correlated with the short periods. Therefore, it is concluded the negative velocity maxima are associated with short periods and low wave heights. The secondary waves occur after the passage of the primary wave crest and have a peak near the trough of the primary wave; the velocities associated with the primary wave would be negative maximum in this region so that the measured velocity, which is a sum of the primary and secondary waves, can be small or negative. 



\section{CONCLUSIONS}

Waves in the surf zone are a highly non-linear process which is evidenced by the appearance of secondary waves. The secondary waves appeared in the PDFs at the first harmonic of the primary period.

The joint probability density functions of the breaking wave properties show high correlations. The correlation factor ranged between 0.60-0.80 for periods and heights and suggests that the greater the wave period, the higher the breaker height will be. High correlation between the periods and velocities and the heights and velocities suggests that the maximum onshore velocities are a function of wave periods and breaker heights.

Breaking waves may be viewed as a gradation between two extremes, spilling and plunging breakers. The difference between the spilling and plunging breakers becomes apparent in the joint PDFs. The spilling breakers yield a joint PDF which has only one high density contour region, whereas the plunging breakers show two high density contour groups. The high density contour groups appear to be most associated with the period PDF.

The joint PDF $(P(T, H))$ of spilling breakers has a maximum density at a wave period equal to one half the peak period of the wave energy density spectrum, i.e. the first 

harmonic. The corresponding velocities $(\mathrm{p}(\mathrm{V}, \mathrm{T}))$ or heights $(p(H, T))$ were likewise found to be unimodal with a peak density which is driven by the first harmonic wave period.

Plunging breakers, at the opposite end of the gradation, yield a bimodal joint PDF. The two major contour groups appear to be a result of the bimodal density distribution of the periods. The two peak densities of the period PDF are representative of the peak of the wave density spectrum and a first harmonic. Due to the high correlation of periods and heights, the corresponding PDF of wave heights appears to be bimodal. The joint PDF of period and velocity and the joint PDF of velocity and height suggests high correlation between these variables. The maximum onshore velocities appear to be correlated with both wave periods and wave heights.

A truncated Rayleigh PDF was found to loosely approximate the empirical period and the height PDFs of spilling breakers. This truncation seems to be the result of long period waves with their associated larger breaker heights breaking prior to the arrival at the wave gauge. The mode of the spilling wave period distributions corresponds to the first harmonic of the peak of the energy density spectrum. The smoothed appearance of the spilling wave periods PDF, relative to the plunging case, appears due to the smearing which occurs with the appearance of harmonics greater than the first. The velocities PDFs of spilling waves, where the velocity maximum is determined as in Section $D$, yields a 

symmetrical distribution with some negative onshore velocities present. Since the Rayleigh distribution is undefined for negative values, the resulting fit of observed data with the theoretical Rayleigh distribution is poor.

The PDFs of the plunging breakers are poorly described by either the Rayleigh PDF or other existing theoretical PDFs such as the Weibull PDF. Theoretical PDFs are unimodal, whereas the empirical PDFs under plunging conditions are strongly bimodal. The high correlation found in the joint PDFs for wave heights and maximum velocities also results in a bimodal distribution both in the velocities and the heights PDFs.

The mean wave period as obtained by the zero-up-cross method in the surf zone is a poor indicator of the mean offshore wave period. Spectral analysis of the breaking waves shows an energy peak corresponding to the primary offshore wave period, but the period PDFs of breaking waves have a strong peak at the first harmonic of the wave spectra peak. Plunging waves had high density peaks in the period PDF corresponding both to the peak of the wave spectrum and to its first harmonic. The result is that the mean of the breaking waves falls between the primary and the first harmonic wave period. The mean period of breaking waves therefore is a poor estimation of the mean period of the incident waves. 



\section{APPENDIX A \\ STATISTICAL PARAMETERS CALCULATED}

1. Due to the variation of sampling frequencies between the different experiments, it follows that some of the other statistical parameters will also vary. A summary of these parameters follows where $f_{N}$ is the Nyquist frequency, $\Delta f$ is the resolution, $\Delta t$ is the interval between samples and $T$ is the length of sampled record in minutes.

\section{DATE}

4 MARCH 1975

5 MARCH 1975

6 MARCH 1975

3 MARCH 1975

29 MAY 1975

16 MARCH 1977

17 MARCH 1977

19 MARCH 1977

3 MARCH 1978

9 MARCH 1978

$$
\underline{f}_{\mathrm{N}}(\mathrm{Hz}) \quad \Delta \mathrm{f}(\mathrm{Hz})
$$

2.5

2.5

2.5

2.0

2.0

2.0

2.0

2.0

2.0

2.0

$$
6.1 \times 10^{-4}
$$

$\Delta t(\mathrm{samp} l e / \mathrm{sec})$

0.200

0.200

0.200

0.256

0.256

0.250

0.250

0.250

0.250

0.250
$\mathrm{T}(\mathrm{min})$

27.3

27.3

27.3

35.0

35.0

34.1

34.1

34.1

34.1

34.1

2. Tables of calculated statistical paraneters follow where

$$
\begin{aligned}
& \eta \quad \text { sea surface elevation (m) } \\
& \mathrm{V}=\text { instantaneous particle velocities (m/sec) } \\
& \mathrm{VI}=\text { maximum onshore particle velocities (m/sec) } \\
& \mathrm{LR}=\text { length of record for calculated statistics (min) } \\
& \varepsilon=\text { spectral width parameter } \\
& \mathrm{H}=\text { wave height (m) } \\
& \mathrm{T}=\text { wave period (sec) } \\
& \mathrm{r}=\text { correlation coefficient }
\end{aligned}
$$$$
\text { VII = maximum onshore particle velocities (m/sec) }
$$ 



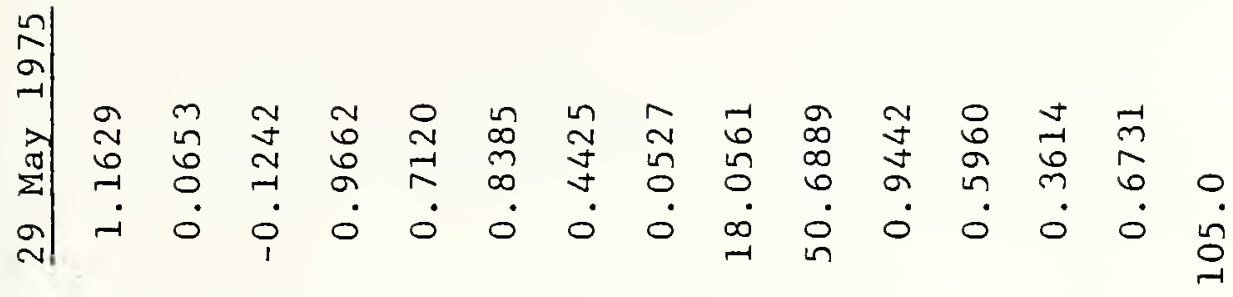

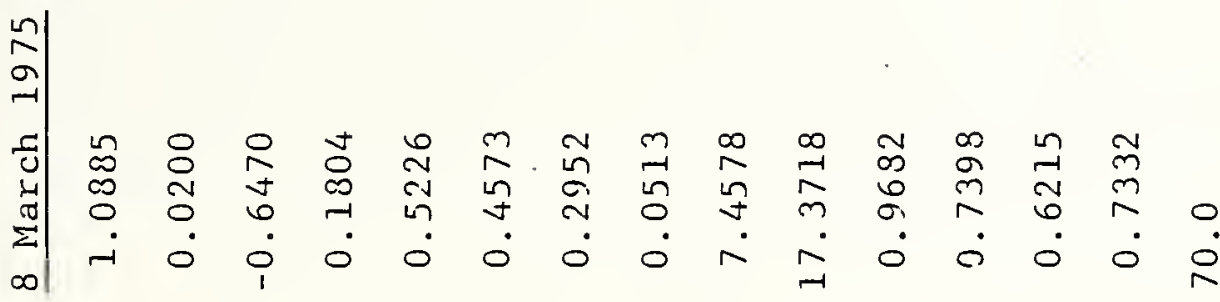

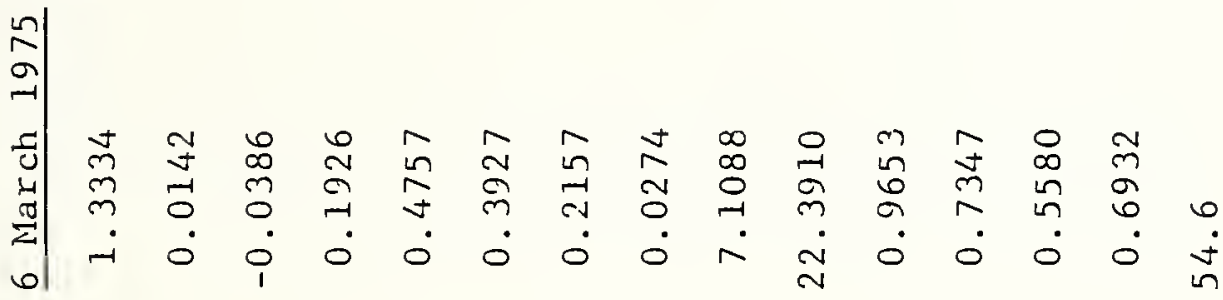

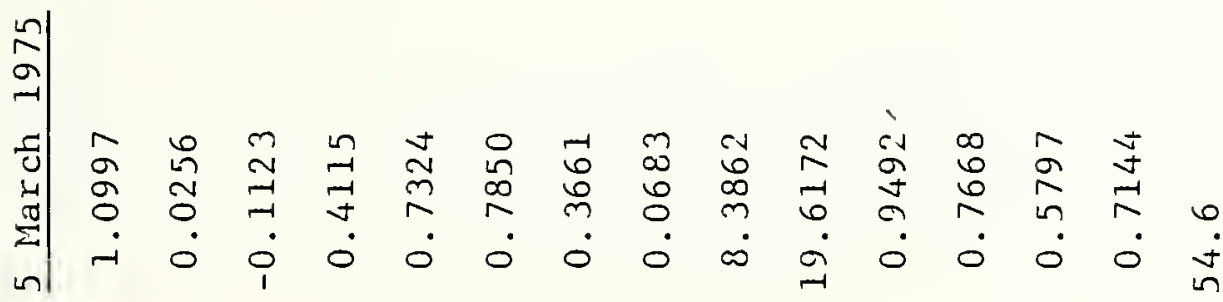

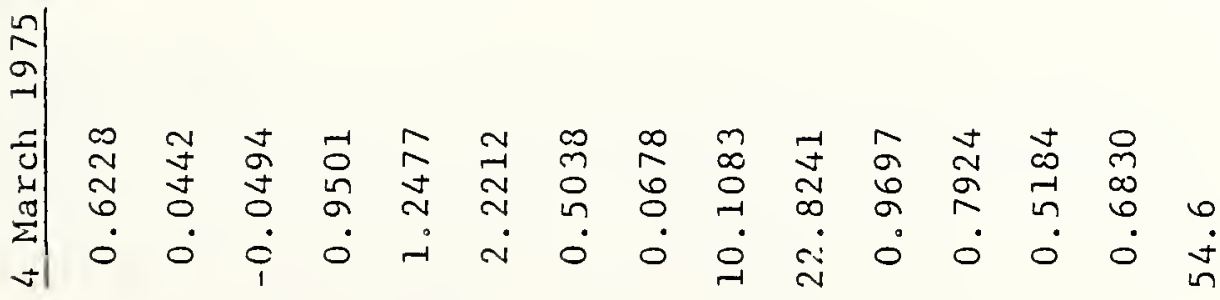

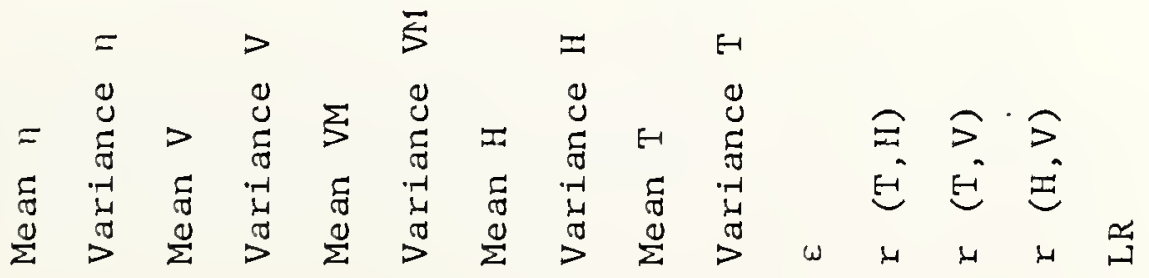





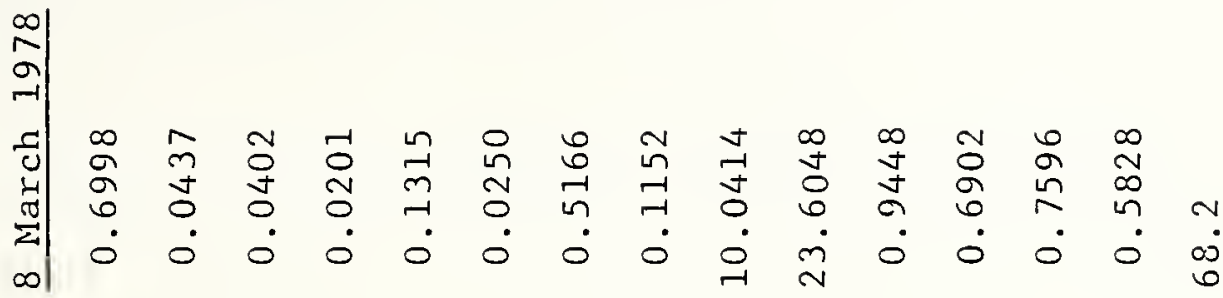

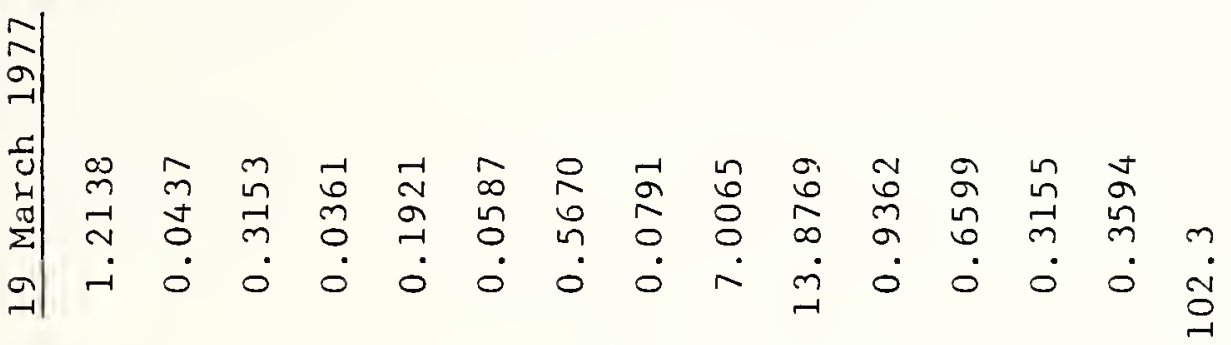

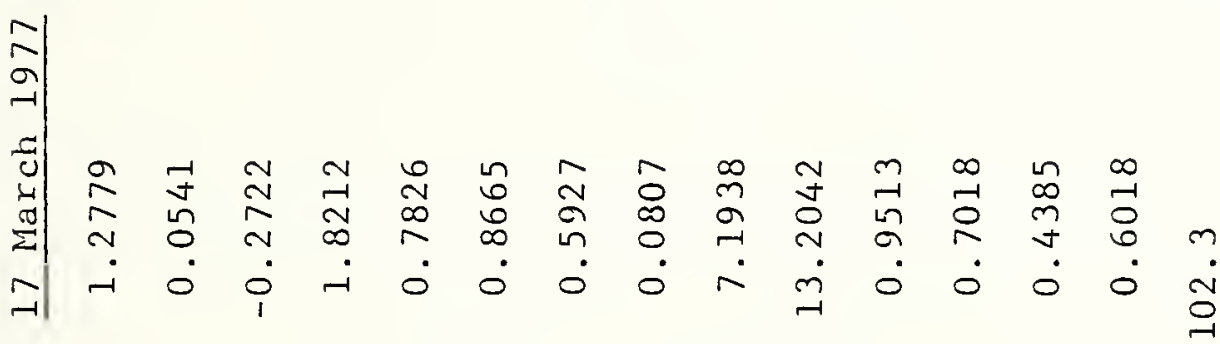

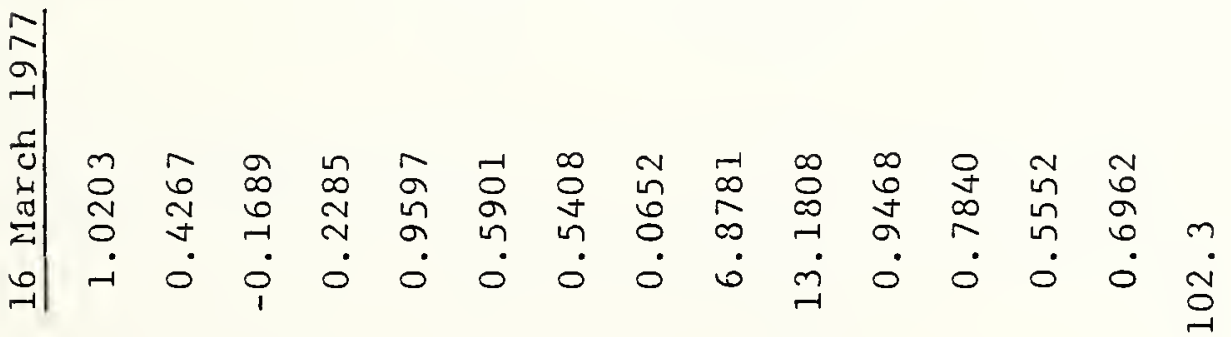

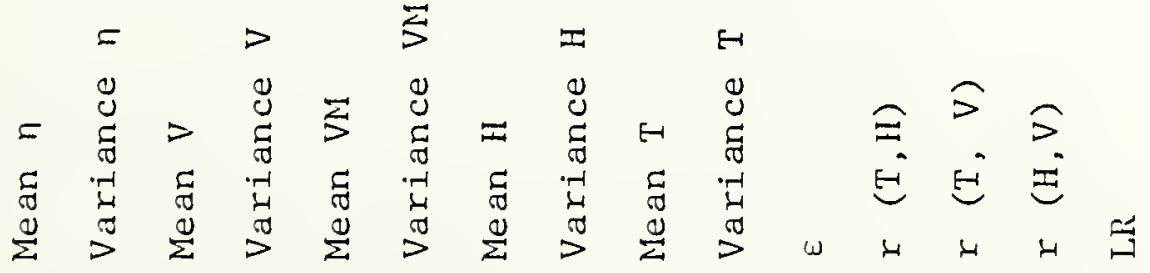





\section{APPENDIX B}

MATHENATICAL DERIVATION OF NORMALIZED RAYLEIGH DISTRIBUTIONS

Wave heights, periods and velocities have been compared with the Rayleigh distribution

$$
p(A)=\frac{A}{4 \sigma^{2}} \exp \left(-\frac{A^{2}}{2 \sigma^{2}}\right)
$$

where $A$ is the non-normalized value. Since all parameters are normalized in this paper, the following conversion was made :

let $A^{\prime}=A / \sigma$,

then

$$
\begin{aligned}
& p\left(A^{\prime}\right)=p(A)\left(\frac{d A}{d A^{\prime}}\right) \quad A=A^{\prime} \sigma \\
& p\left(A^{\prime}\right)=p(A) \frac{d\left(A^{\prime} \sigma\right)}{d A^{\prime}}=p(A) \sigma
\end{aligned}
$$

for wave heights

$$
\begin{aligned}
& \mathrm{p}(\mathrm{H})=\frac{\mathrm{H}}{4 \sigma_{n}} 2 \exp \left(-\frac{1}{2}\left(\frac{\mathrm{H}}{2 \sigma_{n}}\right)^{2}\right) \\
& \mathrm{p}\left(\frac{\mathrm{H}}{\sigma_{\eta}}\right)=\frac{\mathrm{H}}{4 \sigma_{n}} \exp \left(-\frac{1}{2}\left(\frac{\mathrm{H}}{2 \sigma_{n}}\right)^{2}\right)
\end{aligned}
$$

for maximum velocities

$$
\begin{aligned}
& \mathrm{p}(\mathrm{V})=\frac{\mathrm{V}}{4 \sigma_{\mathrm{V}}}{ }^{2} \exp \left(-\frac{\mathrm{I}}{2}\left(\frac{\mathrm{V}}{2 \sigma_{\mathrm{V}}}\right)^{2}\right) \\
& \mathrm{p}\left(\frac{\mathrm{V}}{\sigma_{\mathrm{V}}}\right)=\frac{\mathrm{V}}{4 \sigma_{\mathrm{V}}} \exp \left(-\frac{1}{2}\left(\frac{\mathrm{V}}{2 \sigma_{\mathrm{V}}}\right)^{2}\right)
\end{aligned}
$$

for periods

$$
p(T)=\frac{T}{4 \sigma^{2}} \exp \left(-\frac{1}{2}\left(\frac{T}{2 \sigma}\right)^{2}\right)
$$



where

$$
\begin{aligned}
\sigma & =\overline{\mathrm{T}} / 2 \\
P\left(\frac{\mathrm{T}}{\overline{\mathrm{T}}}\right) & =\frac{\mathrm{T}}{4 \sigma^{2}} \exp \left(-\frac{1}{2}\left(\frac{\mathrm{T}}{2 \sigma}\right)^{2}\right)
\end{aligned}
$$

then

$$
p\left(\frac{T}{T}\right)=\frac{T}{\bar{T}} \quad \exp \left(-\frac{1}{2}\left(\frac{T}{\bar{T}}\right)^{2}\right)
$$





\section{APPENDIX C \\ PROBABILITY DENSITY FUNCTIONS}

The following tables consist of both the normalized joint probability density functions, and the individual probability density functions as labeled. The PDF tables coincide with Figures 5 thru 11, respectively.

The top table is the joint PDF. The top line and the left column represent the center period, height, or velocity point of each of the 15 bins. The numbers in the other colums and lines represent the frequency of occurrence in the respective bins.

The bottom table represents the individual PDFs as labeled. The top line of the individual PDFs is the center point of the individual bins. The second line represents the frequency of occurrence in the bin. 


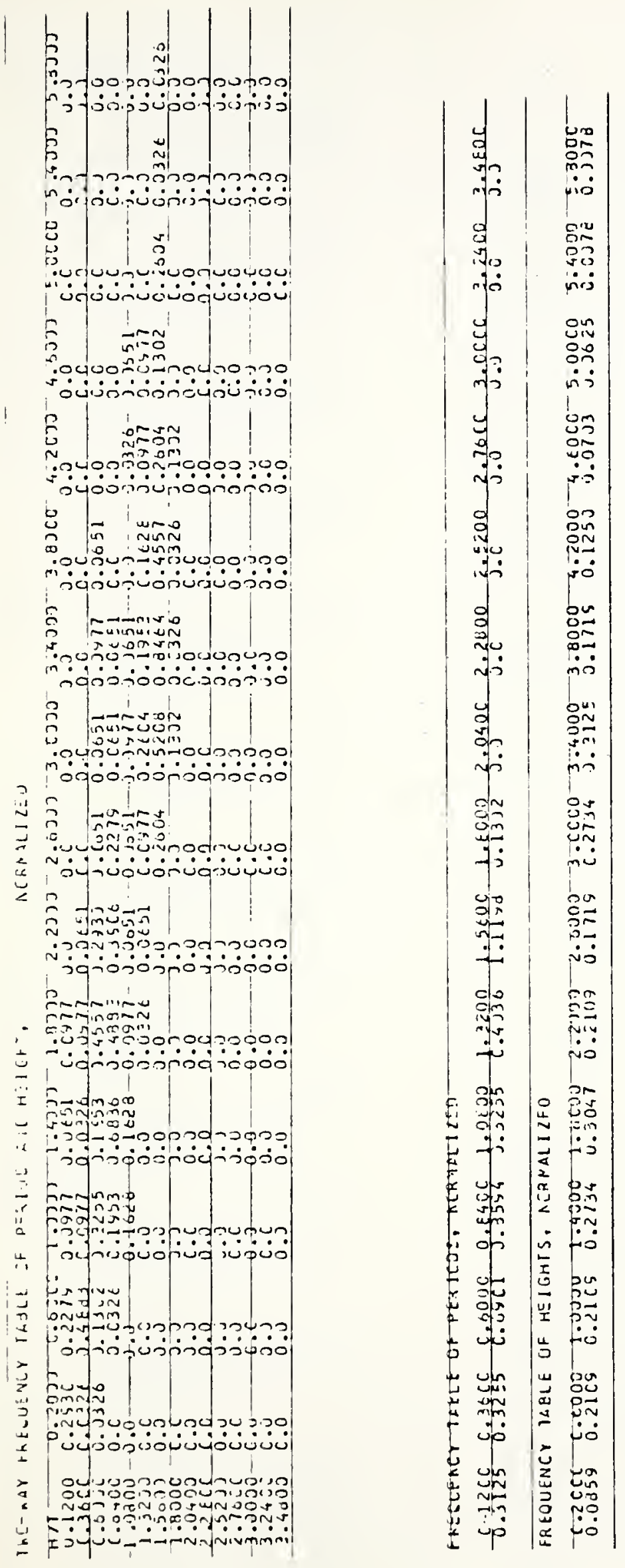

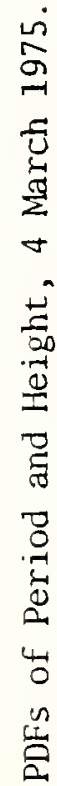




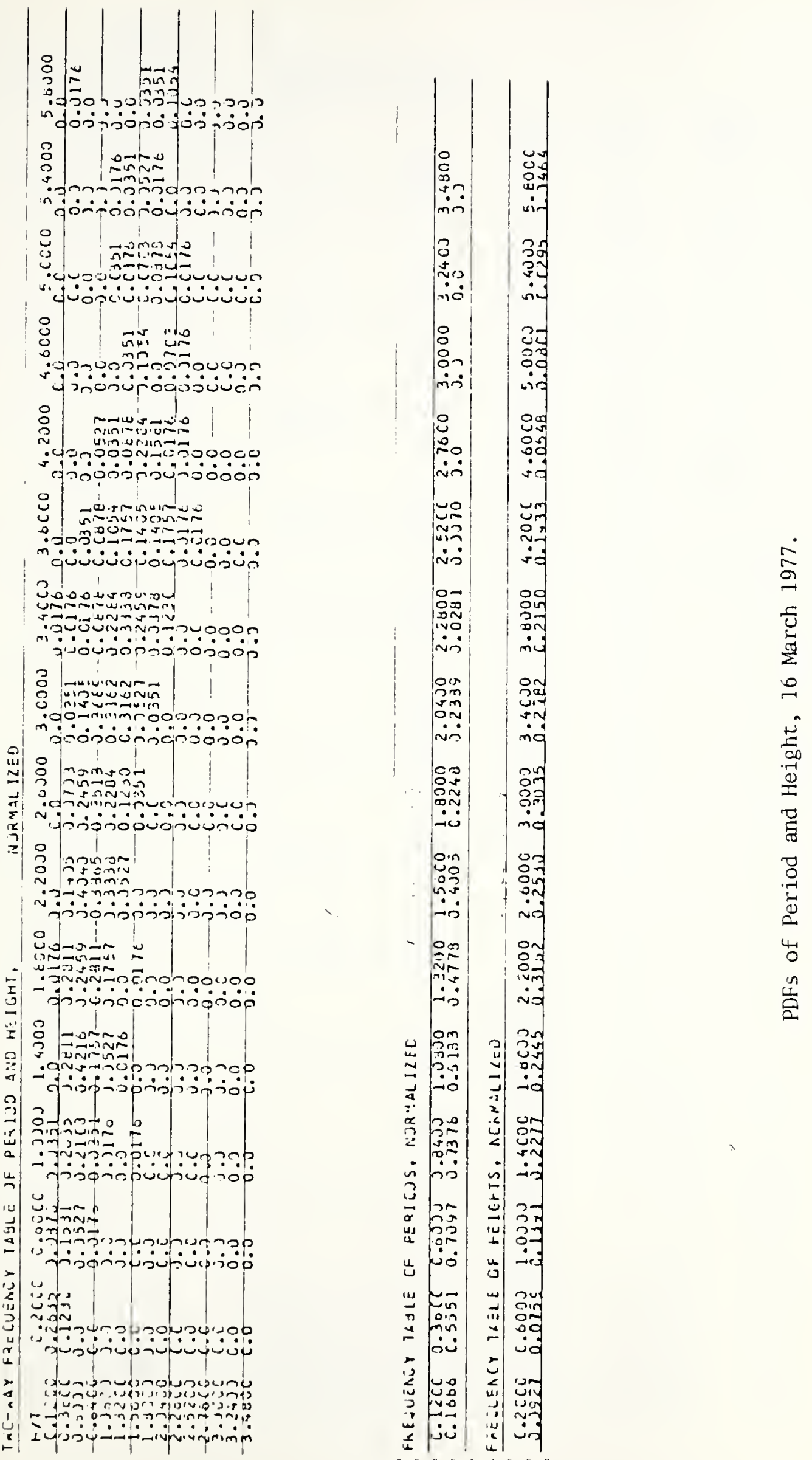

O

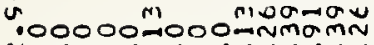
"ióvióóóócióó 옹 1 ज़

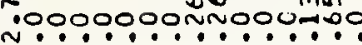
º́óiuóuióióio

응

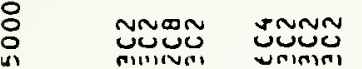
ข. wo.?

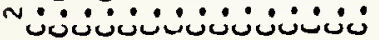

O nounnumunuono ó00نóioviojóo

O

iunumviniunumu

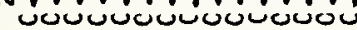

8 s Nnigur

\% 0 üuvio

onoo-ninn-1000000 - نóicóicóióvó:

\& nNytomannN

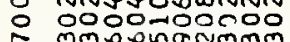

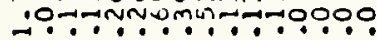

000000000000000

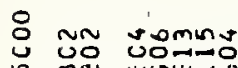

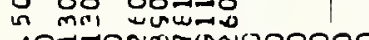

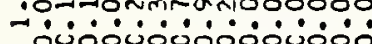

茨 0

Õ̃

บ 이잉

moonommontonotoo

- ́óóóóóóóóóó

요

onnnnugunan

OOyo ivounou

-namanunuma

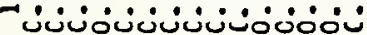

언

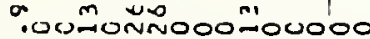

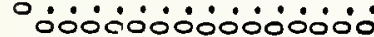

o momnín

añoror

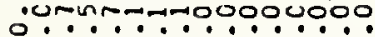

ovovoojovo00000

- Nous'

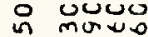

- onnnsonososooo

ojóricisoojióió 0

Sivon N

ouvo o

0 - 10000000000

- jóóóóóóó00.

웅

ดั0̃

Iimm

m-0000000000000

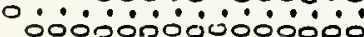

000000000000000

yon

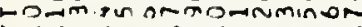

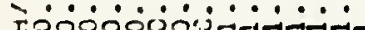

웅

.000000000000000

ióóóóóóóoioió

웅

1000000000000000

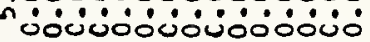

웅

"óverouveropuruo

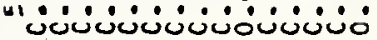

:

ivouvunouvouvouo

"íóóóó

음

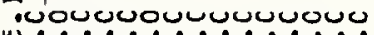

1

웅

웅

.000000000000000

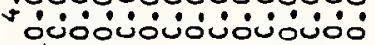

응

.000000000000000

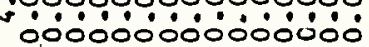

응

1000000000000000 ¿0000000000000

용

m.000000000000000

- íóóóóóóóóóóó

음

일

- 100000000000000

* ن́cicóióióicisi

号

v.

m óóóóóócóóóció

8

ๆu00000000u00000

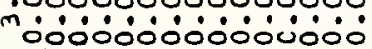

웅

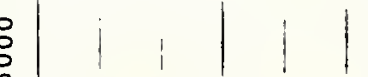

".000000000000000

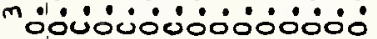

○

.000000000000000

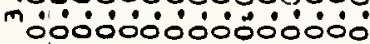

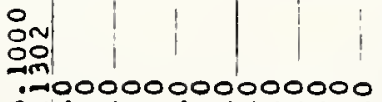

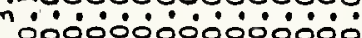

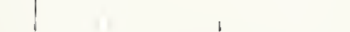

000000000000000

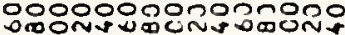

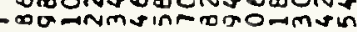

I-Anininininimimin

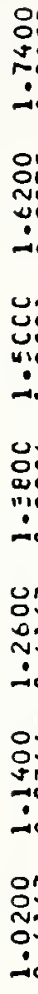

온

no

mo

$\stackrel{\circ}{\circ}$

vis

U.

mó

๖

nio

1
0
0
0
0
0
nio

nio

용

no

응

ก.

Nó

응

요

80

कें

응

프

is

un

Un:

Do

ó

우

워

inu?

ó

요

Nen

am

i

요

요

mm

岩

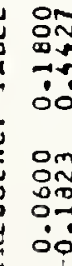

웅

no

웅

ino

nis

웅

jo

vंo

nó

웅

กิ

กं

임

กั०

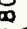

:0

sin

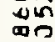

$\therefore \circ$
용

(1)

niy

유에

엉

nio

움

응

$\because 9$

on

ำ

jó

난

o0

1. on

mo 岃

오

in

○点

요

이 Nㅏㄴ

ก:

임 

(?)

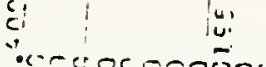

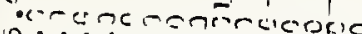

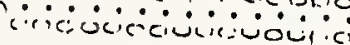<smiles>[C]1CCCC1</smiles>

$\because \because \pi 640$

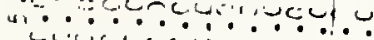

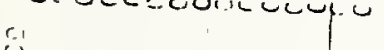

is

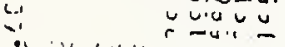

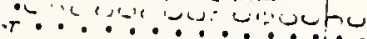

ockivenacocic

ל.

पूu

느는.

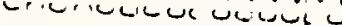

ลิ rutur

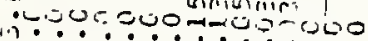

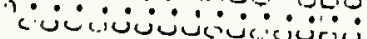

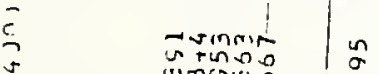

2 minnosing

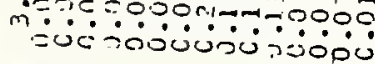

i n-nar-ar in

u nañwwan wn

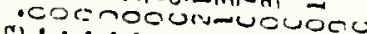

ᄂ

ériojejijujujoi

$\because 3$

Sumintin

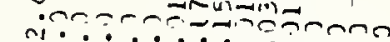

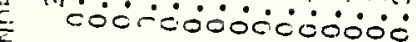

c) inotrunon tin

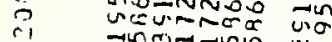

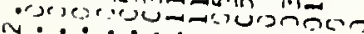

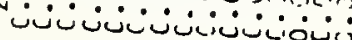

$=2$

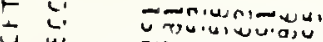

worarumurar

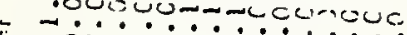

ocrícinivosirio

\& 3 g vomm un

2 -7rs?

- onanuvuvijuoje

3 in

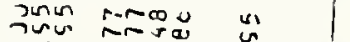

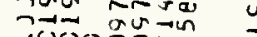

u - 7 .

4.

a 4 -

\&

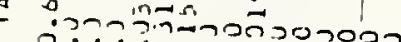

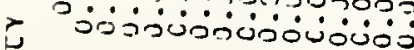

䏚了

amin

«

טذنंsisiósió

3

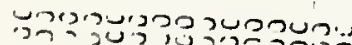

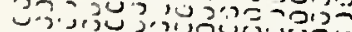

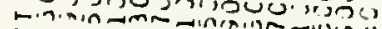

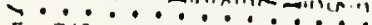

ETijuon-innininins

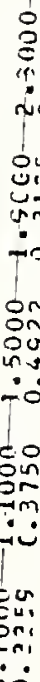

ño

Sin

?त:

to

iun

isin

in

이

$\therefore$

in

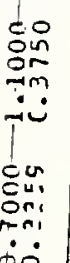

oo

은

on ná

亥 


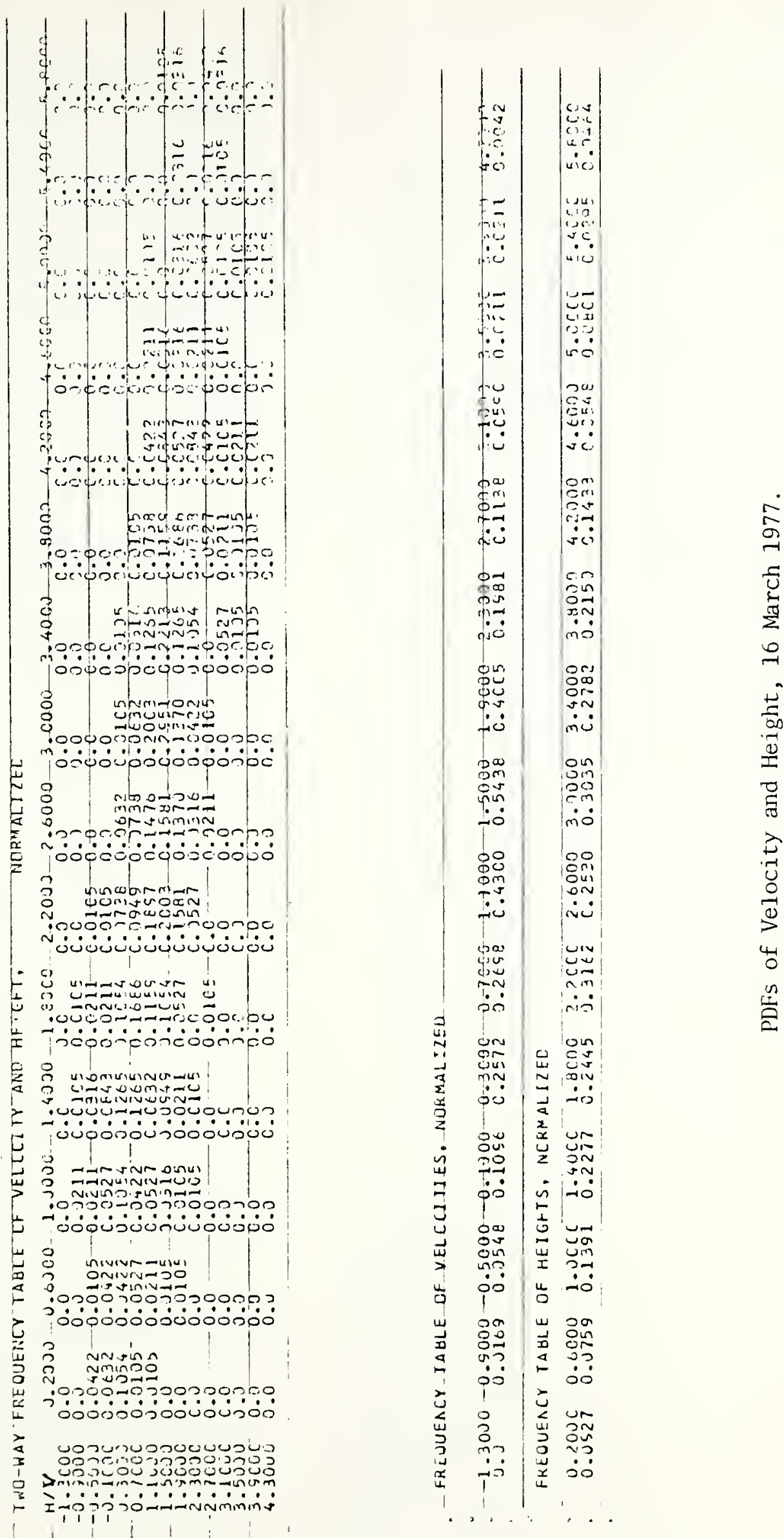




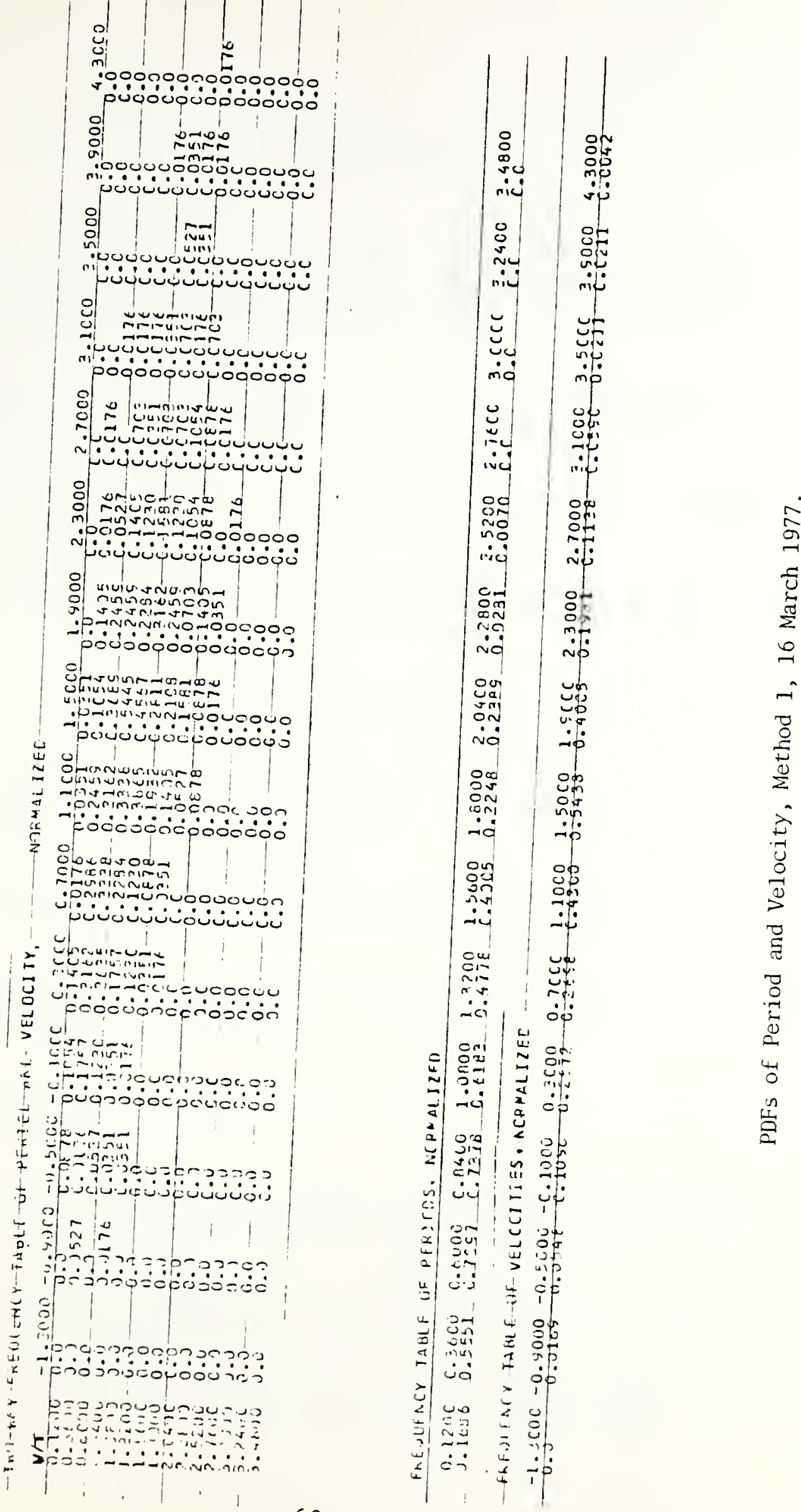





\section{BIBL IOGRAPHY}

Black, K. P., "Wave Transformation over Shallow Reed, (Field Measurements and Data Analysis)," James K. K. Look

Laboratory of Oceanographic Engineering, Department of Ocean Engineering, University of Hawaii, Technical Report No. 42, March 1978.

Bretschneider, C. L., "Wave Variability and Wave Spectra for Wind Generated Gravity Waves," U. S. Army Corps of

Engineers, Tech. Memo 118, 1959.

Cartwright, D. E., and M. S. Longuet-Higgins, "The Statistical Distribution of the Maxima of a Random Function," Proc. Roy. Soc., Ser A, 237, pp. 212-232, 1956.

Chakrabarti, S. K. and R. P. Cooley, "Statistical Distributions of Periods and Heights of Ocean Waves," Jour. of Geophysical Research, Vol. 32, p. 9, 20 March 1977.

Collins, J. I., "Probabilities of Breaking Wave Characteristics," Proc. Conf. on Coastal Engineering (Washington, DC, September 1970), pp. 399-412, 1970.

Davidson, K. L., An Investigation of the Influence of Vater Waves on the Adjacent Airflow, Ph.D. Dissertation, University of Michigan, 1970.

Gallagher, B., "Some Qualitative Aspects of Nonlinear Wave Radiation in a Surf Zone," Geophysical Fluid Dynamics, Vol. 3, pp. 347-354, 1972 .

Galvin, J. J., Rinematics of Surf Zone Breaking Waves; Measurement and Analysis, M.S. Thesis, Naval Postgraduate School, Monterey, California, 1975.

Goda, Y., "Some Results of Observations on Wave Statistical Properties," Rept. of Port and Harbor Res. Inst., No. $39,1967$.

Goda, Y., "Numerical Experiments on Wave Statistics with Spectral Simulation," Report of the Port and Harbour Research Institute, Vol. 13, pp. 3-57, September 1970.

Kinsman, B., Wind Waves Their Generation and Propagation on the Ocean Surface, Pp. 342-352, Prentice-Hall, 1965.

Koele, L. A. and P. A. de Bruyn, "Statistical Distribution of Wave Heights in Correlation with Energy Spectrum and Wave Depth," Proc. of 9 th Conf. on Coastal Eng., A.S.C.E., 1964. 

Kuo, C. T. and S. J. Kuo, "Effect of Wave Breaking on Statistical Distribution of Wave Heights," Proc. Conf. on Coastal Engineering (Copenhagen, Denmark, June 1974), pp. 377-389, 1974 .

Longuet-Higgins, M. S., "On the Statistical Distribution of the Heights of Sea Waves," Journal of Marine Resources, Vo1. 11:3, pp. 245-266, 1952 .

Longuet-Higgins, M. S., "The Effect of Non-Iinearities on Statistic Distributions in the Theory of Sea Waves," 3, Journal Fluid Mech. 17, 459-480, 1963.

Longuet-Higgins, M. S., "On the Joint Distribution of the Periods and Amplitudes of Sea Waves," Journal of Geophysical Research, Vol. 80:18, pp. 2688-2694, 20 June 1975.

Olsen, A. J., The Kinematics of Breaking Waves in the Surf Zone, M. S. Thesis, Naval Postgraduate School, Monterey, California, 1977.

Miller, R. L., "Role of Vortices in Surf Zone Predictions: Sedimentation on Wave Forces," Society of Economic Paleontologists and Mineralogists, 1976.

Siefert, W., "Wave Investigation in Shallow Water," Proc. of 12th Conf. on Coastal Engineering, A.S.C.T., $\frac{1970 .}{19}$

Tayfun, M. A., "Linear Random Waves on Water of Nonuniform Depth," Ocean Engineering Report No. 16, Part II,

Department of Civil Engineering, University of Delaware, Newark, DE, August 1977.

Thornton, E. B., J. J. Galvin, F. L. Bub and D. P.

Richardson, "Kinematics of Breaking Waves Within the Surf Zone," Proc. of the 15th Conf. on Coastal Engineering, pp. 461-476, A.S.C.E., July 1976. 

1. Defense Documentation Center

Cameron Station

Alexandria, Virginia 22314

2. Library, Code 0142

Naval Postgraduate School

Nonterey, California 93940

3. Assoc. Professor E. B. Thornton, Code 68Tm 2 Department of Oceanography

Naval Postgraduate. School

Monterey, California 93940

4. Prof. W. C. Thompson, Code 68Th

Department of Oceanography

Naval Postgraduate School

Monterey, Califomia 93940

5. Chairman, Department of Oceanography

Code 68

Naval Postgraduate School

Monterey, California 93940

6. IT. George Schaeffer III, USN

112 Cortelyou Avenue

Montrose Manor

Reading, Pennsylvania 19607

7. Oceanographer of the Navy

Hoffman Building No. 2

200 Stovall Street

Alexandria, Virginia 22332

3. Office of Naval Research, Code 410

IIORDA

NSTL Station, Mississippi 39529

9. Dr. Robert E. Stevenson

Scientific Liaison Office, ONR

Scripps Institution of Oceanography

La Jolla, California 92037

10. Library, Code 3330

Naval Oceanographic Office

Washington, D. C. 20373 

11. SIO Library

University of Califomia, San Diego

P. O. Box 2367

I.a Jolla, Califomia 92037

12. Department of Oceanography Library

Iniversity of Washington

Seattle, Washington 98105

13. Department of Oceanography Library

Oregon Staté University

Corvallis, Oregon 97331

14. Commanding Officer

Fleet Numerical Weather Central

Monterey, Califomia 93940

15. Commanding officer

Naval Environmental Prediction Research Facility

Monterey, California 93940

16. Department of the Navy

Commander Oceanographic System Pacific

Box 1390

FPO San Francisco 96610

17. Director, Naval Oceanography and Me teorology

National Space Technology Laboratories IISTL Station, Mississippi 39529

13. Naval Oceanographic Research and Development Activity NisTL Station, Mississippi 39529 



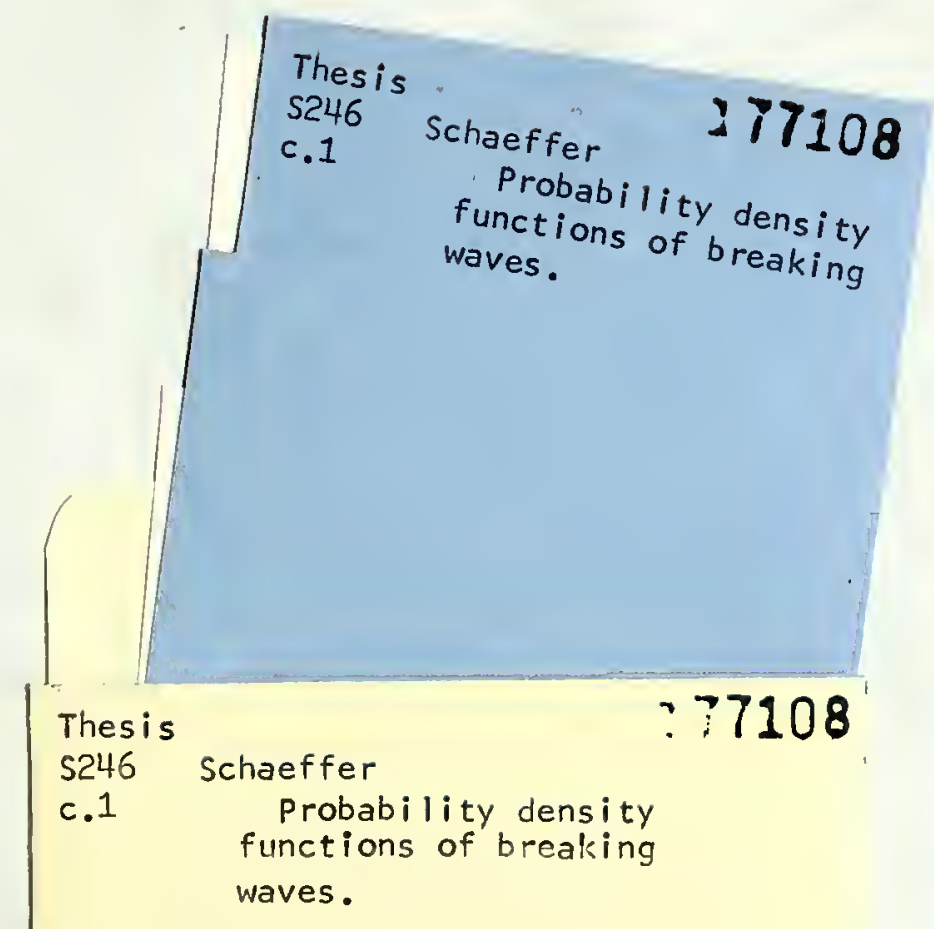


thes\$246

Probability density functıons of breakın

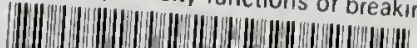

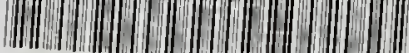

32768002003154

DUDLEY KNOX LIBRARY 